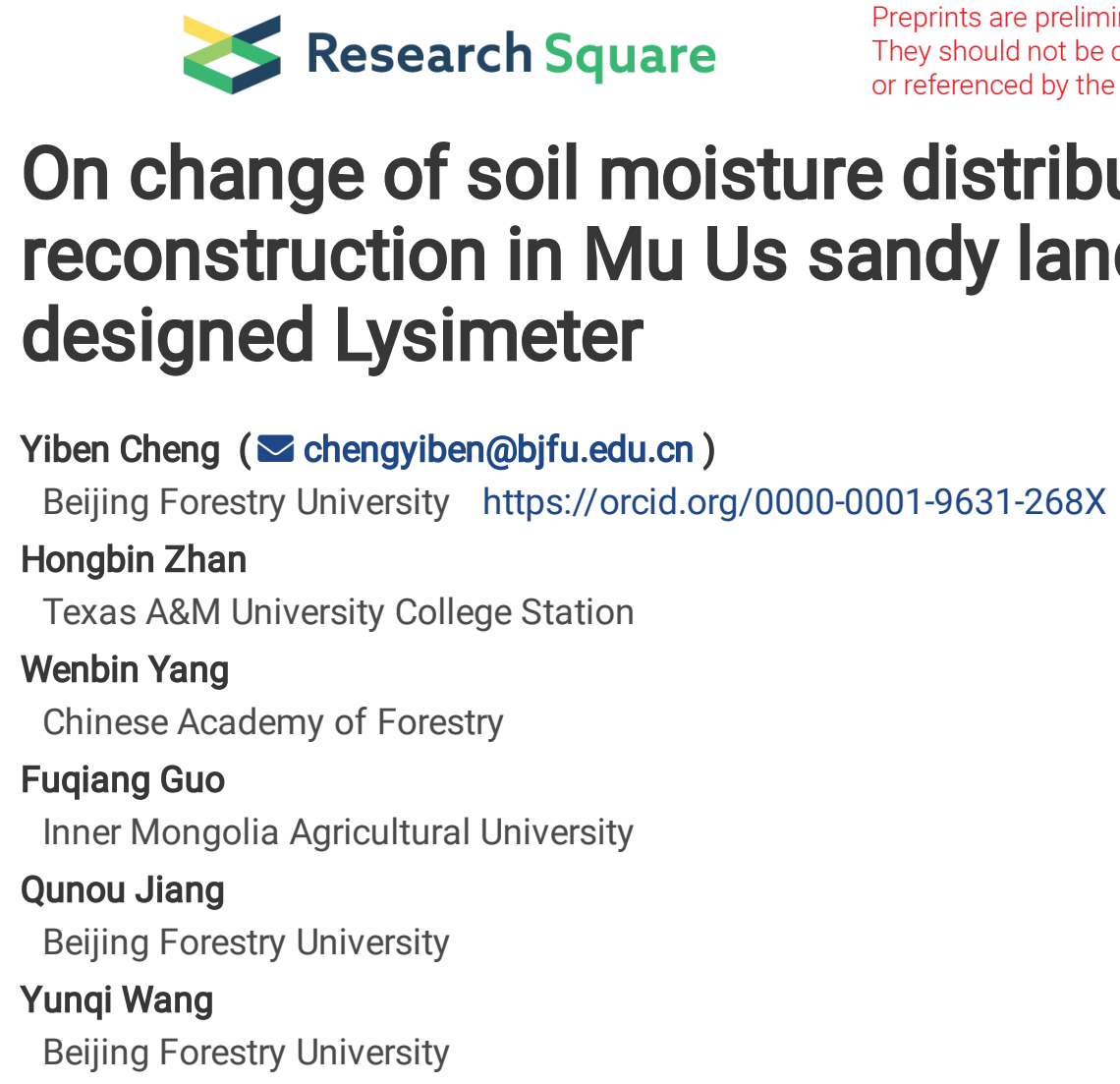

Yiben Cheng ( $\nabla$ chengyiben@bjfu.edu.cn )

Beijing Forestry University https://orcid.org/0000-0001-9631-268X

Hongbin Zhan

Texas A\&M University College Station

Wenbin Yang

Chinese Academy of Forestry

\section{Fuqiang Guo}

Inner Mongolia Agricultural University

\section{Qunou Jiang}

Beijing Forestry University

\section{Yunqi Wang}

Beijing Forestry University

\title{
On change of soil moisture distribution with vegetation reconstruction in Mu Us sandy land of China, with new designed Lysimeter
}

\section{Research}

Keywords: Rainfed Pinus sylvestris var. Mongolia, Infiltration, Semi-arid region, DSR, Soil moisture

Posted Date: August 12th, 2020

DOI: https://doi.org/10.21203/rs.3.rs-56806/v1

License: (ㄷ) (i) This work is licensed under a Creative Commons Attribution 4.0 International License. Read Full License 


\section{Abstract}

Background China's so-called Three North Shelterbelt Program (3NSP) has produced a vast area of lined forest reconstruction in the semi-arid regions. This study uses the lined rain-fed Pinus sylvestris var. mongolica (PSM) sandfixing forest in the eastern part of Mu Us sandy land in Northwestern China as an example. Rain gauges, newly designed lysimeters and soil moisture sensors are used to monitor precipitation, deep soil recharge (DSR) and soil water content, where DSR specifically refers to recharge that can reach a depth more than $200 \mathrm{~cm}$ and eventually replenish the underneath groundwater reservoir.

Results This study shows that there are two obvious moisture recharge processes in an annual base for the PSM forest soil: a snowmelt-related recharge process in the spring and a precipitation-related recharge process in the summer. The recharge depth of the first process can reach $180 \mathrm{~cm}$ without DSR occurring (in 2018). The second process results in noticeable DSR in 2018. Specifically, the DSR values over 2016-2018 are $1.4 \mathrm{~mm}, 0.2 \mathrm{~mm}, 1.2 \mathrm{~mm}$, respectively. To reach the recharge depths of $20 \mathrm{~cm}, 40 \mathrm{~cm}, 80 \mathrm{~cm}, 120 \mathrm{~cm}, 160 \mathrm{~cm}$, and $200 \mathrm{~cm}$, the required precipitation intensities have to be $2.6 \mathrm{~mm} / \mathrm{d}, 3.2 \mathrm{~mm} / \mathrm{d}, 3.4 \mathrm{~mm} / \mathrm{d}, 8.2 \mathrm{~mm} / \mathrm{d}, 8.2 \mathrm{~mm} / \mathrm{d}$, and $13.2 \mathrm{~mm} / \mathrm{d}$, respectively. The annual evapotranspiration in the PSM forest is $466.94 \mathrm{~mm}$ in 2016, $324.60 \mathrm{~mm}$ in 2017, and $183.85 \mathrm{~mm}$ in 2018.

Conclusions This study concludes that under the current precipitation conditions (including both dry- and wet- years such as 2016-2018), water consumption of PSM somewhat equals to the precipitation amount, and PSM has evolved over years to regulate its evapotranspiration in response to annual precipitation fluctuations in Mu Us sandy land of China.

\section{Introduction}

Land degradation is a global threat that impacts the livelihoods of millions of people (Reynolds et al., 2007). The true cost of land degradation is frequently underestimated due to unknown scales of external and downstream impacts (Cao et al., 2011). Sandstorms happen when strong winds impact the arid and semi-arid regions (Sun et al., 2015;Wang et al., 2010a), and they can occur relatively close to the ground surface or rise to kilometers high into the atmosphere and transport very long distances (Wu et al., 2013). Sandstorms can significantly impact human health, agriculture and transportation networks, to name a few (Wang et al., 2013). Agroforestry is a proven approach to battle land degradation or even eradicate sandstorms in some areas, but agroforestry taxes heavily on water resources in arid and semi-arid regions, which may cause other unwanted environmental problems(García Chevesich et al., 2017;Bargués Tobella et al., 2014). Soil moisture is a vital component in the ecological environment and is the source of life for plants on the earth surface (Sharma and Sharma, 2005). On the land surface of the Earth, not only the natural vegetation distribution is limited by water supply, but also the production of artificial vegetation relies on water supply more than any other factors (Gerten et al., 2004;Contreras et al., 2011). Therefore, the dynamic relations among soil, vegetation and soil moisture and the study on their regulation mechanism are of great concern in various disciplines like forestry, agriculture, livestock, and environment (Young, 1989; Li et al., 2013b). For instance, the research in this field in the past decade has profoundly influenced the economic development strategies of arid and semi-arid regions (Cao et al., 2011), and lessons learnt can be applicable for management of arid and semi-arid regions in other parts of the world as well.

Pinus sylvestris var. mongolica (PSM) is a geographical variant of European red pine in the Far East (Bao, 2015;Li et al., 2004). It is naturally distributed in large areas of China's humid and semi-humid areas, especially Daxinganling in the northeast. It inherits the original European red pine's adaptive ability to a variety of ecological environments, and has characteristics such as heliophile, drought-resistant, cold-resistant, soil infertility-resistant and is more resilient to water shortage. It is one of the most common species used in the so-called Three North Shelterbelt Program (3NSP) in China (Zhu et al., 2006). Since the start of 3NSP in 1978, PSM has been introduced and planted on a large scale in the windy 
and sandy areas in the Northeast, Northwest, and North China (Runnström, 2000) and this is why we choose it as an example to study. Up to present, it has been applied in more than 300 counties across 13 provinces, municipalities and autonomous regions in China, with a total area over $3 \times 10^{5} \mathrm{hm}^{2}$ (Hu et al., 2008). Studies have shown that a few countries such as China and India have made great achievements in sand prevention and control by planting sand-fixing forests such as PSM in a massive scale. China and India alone have contributed one-third of the world's new vegetation coverage, and $42 \%$ and $32 \%$ of China's new vegetation coverage areas are forest and agricultural land, respectively. The expansion of green areas in India is mainly due to the expansion of agricultural land (82\%), and the contribution of forests is smaller than that in China (4.4\%) (Bawa et al., 2010;Menon et al., 2002). However, even with such an noticeable achievement, there are still grave concerns in managing windbreak and sand-fixation rain-fed forests (Wang et al., 2010a;Cao et al., 2011; Wang et al., 2010b). For example, reforestation is not successful in some places in 3NSP with unclear reasons. Specifically, trees grow into dwarf trees, which are ineffective in battling land degradation, or even die.

In an attempt to understand why the reforestation effect is successful in some regions and unsuccessful in some other regions, researchers carry out extensive investigations. Some previous studies focus on a number of issues such as transpiration of a single plant such as PSM, interrelationship of atmospheric moisture and PSM in arid regions, and physiological mechanism of PSM to utilize water resources under drought stress (Song et al., 2014). PSM changes soil nutrients in various soil layers and regional soil particle sizes after afforestation (Zeng et al., 2009). Furthermore, there are evidences that PSM in sandy land not only fixes the sand, but also changes the microclimate of the sandy land (Zhao et al., 2012), including transpiration in main growing season of PSM and its relationship with canopy micrometeorology (Zheng et al., 2012). Seasonal water consumption characteristics of PSM are different (Song et al., 2016;Zeng et al., 2009). However, there are relatively few studies on redistribution of precipitation-related regional water resource in soil layers after vegetation restoration using PSM, and infiltration-percolation process in PSM forest in sandy land. Few studies have been conducted on whether the deep soil recharge (DSR) has changed or not in the sandy land after planting PSM, where the DSR refers specifically to recharge that can reach a depth more than $200 \mathrm{~cm}$ below ground surface and may eventually replenish the groundwater reservoir. In-situ experiments will help us unravel the interrelationships of precipitation, surface water, soil water and groundwater after planting PSM in the Mu Us sandy land of China, which will be the objective of this investigation.

To achieve this objective, two central questions have to be answered. First, is there enough precipitation for the reforestation of PSM in battling land degradation in the Mu Us sandy land? (In another word, how does PSM survive the drought years?). Second, what is the change of soil moisture dynamics of sand-fixing PSM forest in a semi-arid region? We will try to answer these questions by inspecting the relationship of precipitation, soil moisture change, and DSR. In particular, if the measured DSR is greater than a certain threshold, meaning that precipitation-induced infiltration can penetrate below the root system of PSM, which is usually shallower than $200 \mathrm{~cm}$ below ground surface in this region, then sustainable reforestation in the region using PSM is possible (Burgess et al., 1998;Bouma and Dekker, 1978). To answer these questions, this study uses a newly developed DSR lysimeter to monitor and analyze a typical PSM forest in the Mu Us sandy land. Specifically, we try to tackle the following issues: 1) the sources of soil water recharge, especially the source of deep soil layer moisture; 2) the precipitation density that causes infiltration and its maximal penetrating depth; 3 ) the rate of annual precipitation-induced infiltration; 4) the evapotranspiration of the PSM forestry. The ultimate goal is to find out whether the rainfed PSM sand-fixing forest can develop sustainably or not in the study site.

\section{Material And Method}

\subsection{Overview of the study area}


The study area is located in Chagan Naoer, on the northeastern edge of Mu Us sandy land $\left(39^{\circ} 05^{\prime} 16.2^{\prime \prime} \mathrm{N}, 109^{\circ} 36^{\prime} 04^{\prime \prime} \mathrm{E}\right)$, as shown in Fig. 1. The Mu Us sandy land mainly consists of semi-fixed and fixed sand dunes, adjacent with the Loess Plateau, located in a desert-loess transitional zone. It has northwestern wind in the winter with a typically dry winter climate and frequent sandstorms. It has southeastern monsoon in the summer. The summer climate is relatively humid, and it is easy to form local heavy precipitation. The multi-year average precipitation is $400 \mathrm{~mm}$, mostly concentrated during the summer. The groundwater table depth varies between $2 \mathrm{~m}$ to $17 \mathrm{~m}$ in the Mu Us sandy land, and it is $8 \mathrm{~m}$ at the experimental area of this study (Runnström, 2003). The groundwater table is lower in the summer and higher in the spring, with a variation less than $1.5 \mathrm{~m}$. Since the initiation of 3NSP at the Mu Us sandy land in 1989, PSM has been planted in lines in the experimental area, with a $10 \mathrm{~m}$ line spacing, an average plant height of $6 \mathrm{~m}$, and an average crown diameter of $6.6 \mathrm{~m}$. The seasonal frozen soil period in the experimental area is from January to April, and from November to December in an annual base (Li et al., 2013a). The soil type in this area is sandy soil and the particle size distribution of $0-200 \mathrm{~cm}$ depth is as follows: coarse sand of $3.23 \%$, middle sand of $50.53 \%$, find sand of $36.06 \%$, very fine sand of $7.19 \%$, and silt sand of $2.99 \%$.

\subsection{Experimental plot design}

The experimental design is shown in Fig. 2. In order to compare and study the soil moisture changes after the vegetation reconstruction of PSM, this study selects a typical PSM forest in the Mu Us sandy land as the research site and selects the adjacent bare sandy land as a comparison study plot. The precipitation, soil water moisture, and DSR have been continuously observed over a three-year period (2016-2018) to answer some of the key questions raised in the introduction of this study.

The canopy of PSM is capable of intercepting precipitation, thus affects the measurements of precipitation and soil moisture underneath the canopy. Therefore, the measurements of this study are made in the middle between the forest lines, measuring precipitation without the interference of the PSM canopy.

When installing the instrument, it is important not to disturb the in-situ soil layer and the PSM root system. In order not to disturb the original structure of the soil layer, we need to pre-water the test plot before installing the instrument. Watering the test plot can help consolidate the sand layer for excavation because the dry sand is easy to collapse. The first step is to excavate a depth of $3 \mathrm{~m}$ soil profile in the middle of two rows of PSM forest with a horizontal cross-section of $0.5 \mathrm{~m}$ by $0.5 \mathrm{~m}$. The reason to excavate a $3 \mathrm{~m}$ depth soil profile is because the depth of the measured soil layer is $2 \mathrm{~m}$ and the height of lysimeter that will be installed below is $1 \mathrm{~m}$. The second step is to install the lysimeter which is $1 \mathrm{~m}$ high, $0.5 \mathrm{~m}$ wide and $0.5 \mathrm{~m}$ long horizontally. The distance from the top of the lysimeter to the ground surface is $2 \mathrm{~m}$. The third step is to use in-situ soil to backfill the excavation. During this backfilling process, we also install soil moisture probes above the lysimeter uniformly over the $200 \mathrm{~cm}$ soil layer with a depth interval of $40 \mathrm{~cm}$ except the shallowest two probes which have a depth interval of $20 \mathrm{~cm}$. One also needs to continuously water the backfilled sands to assist the sand settlement. After the completion of backfill, one needs to wait for one year to make sure that the soil layers can be restored to its preexcavation status as much as possible. As a comparison study, we repeat above procedures and install an identical lysimeter and soil moisture probes in a nearly bare sand plot in exactly the same fashion as in the PSM forest plot. After completing above tasks, one can continuously record and observe the movement of precipitation-induced infiltration in the soil layers of the two test plots. A point to note is that the water table in the site is sufficiently deep ( $8 \mathrm{~m}$ below ground surface) that it will not affect the soil moisture dynamics above the lysimeter, which is exclusively controlled by the precipitation-induced infiltration, root system of PSM, and soil layer structure of the site.

\subsubsection{PSM root system excavating}


Previous studies in this area have shown that PSM has a shallow root distribution and few underdeveloped taproots, the PSM roots are mostly distributed over a vertical range of $0-2.5 \mathrm{~m}$ and rely on precipitation for water supply. The root distribution of PSM can reach $6.5 \mathrm{~m}$ horizontally, with a concentrated area of $3 \mathrm{~m}$. The root distribution characteristics of PSM reflects the source of water supply in this area. In general, if the root is distributed horizontally in the shallow soil, it indicates that precipitation is the main water source; if the root is distributed in the deep soil layers, it indicates that the deep soil moisture is the water supply to PSM. In order to accurately investigate the root distribution of PSM in the Mu Us sandy land, we have excavated five adjacent PSMs which were planted at the same time as the PSM of concern and use them as surrogates to examine the root distribution layer by layer in a $20 \mathrm{~cm}$ depth interval. To avoid root breakage, the sandy soil samples were watered first before being excavated to examine the roots. The roots of each layer were collected and dried and the average biomass of each layer for the five surrogates was calculated and used as the representative biomass of a specified soil layer.

\subsubsection{Soil moisture monitoring}

There are many effects of vegetation on soil, including soil nutrient change and biomass change. A most important reason for planting PSM in this area is to fix sand, thus this study focuses on a key factor affecting the survival of PSM in the Mu Us sandy land - soil moisture. To fulfill this objective, a soil section is cut out in the middle between two forest lines. The section consists of a layer of dead tree leaves, a leached layer, a depositional layer, and a native soil layer, which is of fine sand. According to the soil stratification of PSM, soil moisture probes (EC-5, accuracy $0.1 \% \mathrm{~mm}, \mathrm{USA}$ ) have been placed in soil layers at $20 \mathrm{~cm}, 40 \mathrm{~cm}, 80 \mathrm{~cm}, 120 \mathrm{~cm}, 160 \mathrm{~cm}$, and $200 \mathrm{~cm}$ depths. The measurement interval is one hour. The EC-5 soil moisture probes are used and the correction equation is (Wu et al., 2014):

where $\mathrm{x}_{\text {sand }}$ and $\mathrm{y}_{\text {sand }}$ are the measured value and the corrected soil moisture values, respectively, and the coefficient of determination for above Eq. (1) is $\mathrm{R}^{2}=0.9098$. The topographic variation of the area is almost negligible and long-term observations show that there is no surface runoff. Under low temperature conditions in the winter, the accuracy of soil moisture probes (EC-5) may drop by $5 \%$ (according to the original manufacturer's instruction). To avoid the possibly unreliable data in the winter, this research focuses on analyzing the data from April to November (unfrozen ground period).

The soil moisture probes clearly showed the actual precipitation-induced infiltration in each soil layer. In this study, six soil moisture probes were installed according to the soil stratification to monitor the infiltration rate and depth after each precipitation event. According to the depth of soil moisture migration, the infiltration depth associated with different precipitation intensities during the observation period can be determined. At the same time, according to the soil water content, the soil water retention in each layer can be calculated as well. Surface evapotranspiration can be calculated according to precipitation, soil water retention and DSR.

\subsubsection{DSR monitoring}

The conventional methods to study the process of evapotranspiration focus on the study of the surface evaporation, vegetation transpiration, surface runoff, vegetation interception, etc. In this study, we use a new experimental method to observe the precipitation induced infiltration-penetration process, and directly measure the DSR of the deep soil layer below the root system layer. Through the measurement of water input, soil water storage and deep infiltration as output, the evapotranspiration can be calculated by water balance equation.

To study the soil moisture distribution of PSM in the Mu Us sandy land, two sets of data need to be collected: precipitation from a rain gauge, as input of moisture, and DSR measurement from a lysimeter, as output of moisture. The conventional lysimeter is bulky and expensive, the vegetation to be measured have to be planted in a cylindrical 
container, and the deep soil moisture in the lower part is exported to the measuring part. This new lysimeter has a few innovations (see Fig. 3) that can be outlined as follows. The new design has its upper boundary at a designed depth to measure the amount of DSR (denoted as depth-A). A cylindrical container with a diameter of $50 \mathrm{~cm}$ with impermeable walls called capillary water balance part is installed from depth-A downward to a deeper depth-B. The length of this part is determined according to the capillary rise of the in-situ sandy soil, which can be calculated based on soil hydraulic properties. More specifically, the length of $A B$ is greater than the height of capillary rise and it is usually greater than $0.6 \mathrm{~m}$ (Liu et al., 2014). At the soil surface there is a rain gauge to measure the amount of precipitation and at the base of the instrument (depth-B), a water collection device is used to measure the amount of water (DSR) exiting the base downward (Cheng et al., 2017a).

Before taking the measurements, the lysimeter needs to be placed one year in advance, in 2015, allowing the plot soil to reach its pre-installation condition by going through naturally settlement. The annual precipitation in 2015 was $186.4 \mathrm{~mm}$, which is a dry year. The most advantage of the new lysimeter is to reduce the disturbance of the soil layer above the measurement layer and avoid the influence of the instrument barrier on the lateral flow of soil moisture during the observation stage. The conventional lysimeter has many disadvantages in monitoring large trees as mentioned above. One of such disadvantages is that the closed container will affect the normal growth of the PSM root system. The new instrument does not have this problem. In this study, the new instrument is buried at a depth of $2 \mathrm{~m}$, below the PSM root layer.

\section{Results}

\subsection{Annual characteristics of precipitation - soil moisture variation}

The soil moisture variation of PSM in 2016 is shown in Fig. 4. It reveals that soil moisture has obvious seasonal trends. The soil from January to March is frozen. The near surface soil moisture recharge is from snowmelt. When the near surface frozen soil starts to thaw, soil at the $20 \mathrm{~cm}$ depth is recharged on February 9th, 16th and 26th in 2016. Soil at depths greater than $20 \mathrm{~cm}$ remains relatively stable. Frequent precipitation events usually occur from June to November, during which soil moisture changes considerably, and soil moistures at different depths exhibit periodic increase or decrease, regulated by the interplay of precipitation and evapotranspiration. After February 26th in 2016, soil gradually thaws completely. Figure 4 shows that snowmelt can recharge the soil moisture as deep as $160 \mathrm{~cm}$. The soil moisture at $200 \mathrm{~cm}$ depth is recharged for the first time after a heavy precipitation event on July 8th in 2016.

According to Fig. 4, the soil moisture content of the upper $200 \mathrm{~cm}$ soil layer fluctuates multiple times in 2016. After November, the soil moisture content of the upper $200 \mathrm{~cm}$ soil layer fluctuations but DSR is not detected. This is probably due to the error of the EC-5 probe under frozen winter condition. Therefore, the active research period has been revised to a window from April to November each year. Although the precipitation time and intensity are different in the three year period of observation (2016-2018), the variation trends of soil moisture in each season of the three years are basically the same.

\subsection{Root distribution characteristics of PSM}


Table 1

Vertical distribution of root biomass of PSM

\begin{tabular}{|c|c|c|c|c|c|c|c|c|}
\hline Depth(cm) & $\begin{array}{l}\text { Sample } \\
1\end{array}$ & $\begin{array}{l}\text { Sample } \\
2\end{array}$ & $\begin{array}{l}\text { Sample } \\
2\end{array}$ & $\begin{array}{l}\text { Sample } \\
4\end{array}$ & $\begin{array}{l}\text { Sample } \\
5\end{array}$ & $\begin{array}{l}\text { Average fine } \\
\text { root } \\
\text { biomass(d冈0.2 } \\
\mathrm{cm} \text { ) }\end{array}$ & $\begin{array}{l}\text { Average } \\
\text { total root } \\
\text { biomass(g) }\end{array}$ & $\begin{array}{l}\text { Biomass } \\
\text { precentage } \\
\text { of } \\
\text { Whole } \\
\text { layer }\end{array}$ \\
\hline $0-20$ & 1989.31 & 1845.89 & 2000.21 & 1789.45 & 1879.45 & 1600.86 & 1900.86 & $11.14 \%$ \\
\hline $20-40$ & 5976.45 & 6120.65 & 5789.34 & 6018.83 & 5729.39 & 5646.93 & 5926.93 & $34.75 \%$ \\
\hline $40-60$ & 6783.62 & 6682.50 & 6831.72 & 6391.58 & 6972.91 & 6472.47 & 6732.47 & $39.47 \%$ \\
\hline $60-80$ & 192.83 & 189.31 & 194.38 & 179.37 & 189.30 & 29.04 & 189.04 & $1.11 \%$ \\
\hline $80-100$ & 184.03 & 198.31 & 187.30 & 179.82 & 179.45 & 9.78 & 185.78 & $1.09 \%$ \\
\hline $100-120$ & 168.53 & 157.82 & 165.20 & 177.43 & 165.59 & 0.1 & 164.29 & $0.96 \%$ \\
\hline $120-140$ & 166.65 & 155.43 & 158.45 & 168.38 & 158.41 & 0.1 & 161.46 & $0.95 \%$ \\
\hline $140-160$ & 188.43 & 167.21 & 155.82 & 163.72 & 154.90 & 0 & 166.02 & $0.97 \%$ \\
\hline $160-180$ & 179.78 & 167.66 & 162.60 & 154.72 & 160.80 & 0 & 165.11 & $0.97 \%$ \\
\hline $180-200$ & 154.56 & 155.68 & 153.80 & 161.58 & 153.82 & 0 & 155.89 & $0.91 \%$ \\
\hline $200-220$ & 152.30 & 159.32 & 143.83 & 152.93 & 155.21 & 0 & 152.72 & $0.90 \%$ \\
\hline $220-400$ & 1154.20 & 1042.38 & 1203.75 & 1167.49 & 1212.52 & 0 & 1156.07 & $6.78 \%$ \\
\hline
\end{tabular}

PSM in the study site has one taproot and numerous fine roots. The five excavated PSMs have an average taproot length of $4 \& \mathrm{nbsp} ; \mathrm{m}$, and the vertical distribution of root reflects the water use range of plants. As shown in Table\&nbsp; <span refid="Tab1" class="InternalRef">1</span>, almost all fine roots of PSM are distributed in the shallow soil layer of $0-100 \&$ nbsp;cm depth and the biomass of $0 \&$ ndash; $60 \& \mathrm{nbsp} ; \mathrm{cm}$ root accounts for $85.36 \%$ of all the root biomass. This indicates that PSM is effective to utilize soil moisture in shallow layers, but is less effective to utilize soil moisture below $100 \& n b s p ; c m$. Although the main root of PSM has a depth of nearly 4\&nbsp;m, the fine root biomass on the deep taproot (deeper than 100\&nbsp;cm) is very small. Therefore, PSM in this area can be classified as shallow root species. The root distribution also indicates that precipitation is the main water source for PSM in this area. As $90 \%$ of the fine roots of PSM are distributed in shallow soil layers (with depths less than 100\&nbsp;cm) in which the water moistures generally fluctuate greatly in a daily and seasonal basis, PSM in the Mu Us sandy land is heavily dependent on precipitation events.

\subsection{Water distribution characteristics of individual soil layers}

In order to study the degree of soil moisture response to precipitation in individual layers, this research chooses each layer's soil moisture at the beginning of each month of 2016 as a representative, to observe whether the soil moisture in a specific layer is recharged. Figure 5 shows the soil moistures at depths of $20 \mathrm{~cm}, 40 \mathrm{~cm}, 80 \mathrm{~cm}, 120 \mathrm{~cm}, 160 \mathrm{~cm}$, and $200 \mathrm{~cm}$ at the beginning of each month. From Fig. 5, the soil of PSM exhibits four distinctive layers: an evapotranspiration layer at 0-40 cm depth, a lateral root activity layer at 40-160 cm depth, a relatively dry soil layer at 160-200 cm depth, and a deep soil layer below $200 \mathrm{~cm}$. The soil layer at 160-200 cm depth is usually in a relatively dry state without DSR replenishment, and it will temporarily converted to a relatively wet state when replenishment is obtained either from heavy precipitation events or from soil moisture during the freeze-thaw process. For the 0-40 $\mathrm{cm}$ 
evapotranspiration layer, the soil moisture increases only under the effect of precipitation or snowmelt. Its moisture content decreases rapidly under the interplay of evapotranspiration and infiltration. For the $40-160 \mathrm{~cm}$ root activity layer, the soil moisture is recharged from infiltrated water passing through the upper layer, and it gradually decreases under the effects of infiltration and root moisture absorption. Water absorption of the PSM root system is primarily responsible for depleting the soil moisture for soils at 160-200 cm, resulting in a relatively dry state for this layer of soil. Below the $200 \mathrm{~cm}$, the absorption of the PSM root system diminishes because the PSM root system can rarely penetrate a depth greater than $200 \mathrm{~cm}$. Consequently, the moisture content of the soil at the $200 \mathrm{~cm}$ depth is higher than that at the $160 \mathrm{~cm}$ depth. The deep soil below $200 \mathrm{~cm}$ depth is of native sand soil, and Fig. 5 shows that the soil moisture content of this layer is recharged five times under heavy precipitation events in 2016.

Results show that the shallow soil receives soil moisture replenishment from precipitation, which is quickly converted into evapotranspiration or absorbed by the roots of PSM, with a small amount of precipitation that can reach the deep soil layer. The topsoil moisture of PSM forest changes dramatically, and the $120 \mathrm{~cm}$ soil layer stores more water than the deep soil layer. The soil water content at a depth of $160 \mathrm{~cm}$ is relatively low, and one can conclude that precipitation cannot effectively replenish the deep soil below the $160 \mathrm{~cm}$ depth.

\subsection{Precipitation and DSR distribution}

The total precipitation in 2016 is $506.4 \mathrm{~mm}$, which is higher than the average annual precipitation, thus 2016 is a wet year. As shown in Fig. 6, the precipitation in 2016 is concentrated from July to August, with 86 precipitation events accounted for over the whole year in 2016. The maximum daily precipitation is $137.2 \mathrm{~mm}$ on July 10 th, and the minimum daily precipitation is $0.2 \mathrm{~mm}$ and it occurs multiple days in 2016 . According to the distribution of soil moisture curves in each soil layer in Fig. 6, the moisture content of the soil layer below $120 \mathrm{~cm}$ layer fluctuates during the freezethaw period and the summer rainy season. Before the heavy rain in July 10th, no precipitation could penetrate the $120 \mathrm{~cm}$ depth soil layer, and the freeze-thaw water and precipitation are absorbed by the PSM root system. The results show that there are two replenishment processes of soil moisture, the freezing and thawing replenishment process of surface ice and snow deposits accumulated in winter, and the replenishment process of rainy season precipitation, the heavy precipitation has a significant effect on the replenishment of deep layer soil moisture in this region.

There are only four events of detected DSR in the PSM plot over the entire year in 2016, resulting in an annual DSR of $1.4 \mathrm{~mm}$ in the PSM plot in 2016. As shown in Fig. 7, all the measurable DSR events occur after September 21th, and they are close to the winter freeze-thaw period, during which PSM usually ceases to grow. This implies that there are essentially no DSR events throughout the growing season of PSM in 2016. In comparison, in the bare sandy land plot, there are six measurable DSR events before the maximum precipitation event of July 10th in 2016 . After July 10 th in 2016, there are four considerable DSR events, with a total DSR amount of $281.6 \mathrm{~mm}$. The distinctive DSR difference in the PSM forest plot and the bare sandy land plot shows that the PSM forest absorbs almost all the precipitation-induced infiltration in 2016, while the bare sandy land has a considerable amount of DSR at the same year, which accounts for $55.6 \%$ of the annual precipitation. This means that groundwater recharge is profoundly affected after vegetation reconstruction using PSM in the Mu Us sandy land, even for a wet year like 2016.

The total precipitation in 2017 is $309 \mathrm{~mm}$ (less than the multi-year average precipitation of $400 \mathrm{~mm}$ ), as shown in Fig. 8, which signifies a dry year. There are 32 times observed precipitation events in 2017, as shown in Fig. 8. The maximum daily precipitation is $22 \mathrm{~mm}$ on July 22th, 2017. The soil moisture fluctuation in 2017 is similar to that in 2016. There is a freezing period from January-March, the surface soil freezes, and the soil water content changes in each soil layers are relatively stable. March to April belongs to the freezing and thawing mixed period, frozen water in the soil layer gradually melts. Especially, the surface layer frozen water functions as a reservoir. The frozen water replenishes the soil moisture of each soil layer and the spring snowmelt recharge depth is $140 \mathrm{~cm}$ in 2017. April to November in 2017 is a rainy 
season with dynamic soil water variation. Under the interplay of precipitation-induced infiltration, soil evapotranspiration and vegetation consumption, the soil moisture fluctuates. After the rainy season, the soil begins to freeze again in December. The results show that in 2017, the total precipitation of the PSM forest land is relatively small, and the of a single precipitation is relatively small as well. Before entering the winter season, the precipitation is absorbed by the PSM root system, and no precipitation-induced infiltration can reach the $120 \mathrm{~cm}$ depth soil layer until later winter.

In 2017, the amount of DSR in the bare sandy land is $67.6 \mathrm{~mm}$. In contrast, the amount of DSR in the PSM forest land in the same year is only $0.2 \mathrm{~mm}$, as shown in Fig. 9. Since January $1 \mathrm{st}$ of 2017 , there has been a continuously recognizable DSR signal in the bare sandy land, indicating that the previous year (2016) is a wet year, thus the soil contains a large amount of water and continues to replenish the groundwater reservoir. However, the PSM forest land has a much lower water storage due to the consumption by PSM, and the DSR below the PSM forest has been significantly reduced in 2017. As shown in Fig. 7, the soil moisture fluctuations intensely in the soil layers at $20 \mathrm{~cm}$, $40 \mathrm{~cm}$, and $80 \mathrm{~cm}$ depths. The soil layer from $120 \mathrm{~cm}$ to $200 \mathrm{~cm}$ is relatively stable, and it is only replenished by soil moisture during the freezing and thawing period (March to April). The $120 \mathrm{~cm}$ and $160 \mathrm{~cm}$ depth soil layers are replenished (on 14 October) due to continuous summer precipitation. The $200 \mathrm{~cm}$ depth soil layer remains relatively dry throughout 2017. The annual DSR underneath the PSM forest is only $0.2 \mathrm{~mm}$ in 2017, which is much lower than the DSR for the same plot in 2016. The lack of precipitation in 2017 causes a sharp drop in deep soil moisture infiltration.

The total precipitation amount is $239.8 \mathrm{~mm}$ (greater than the multi-year average precipitation of $400 \mathrm{~mm}$ ) in 2018 , as shown in Fig. 10, which is a dry year. There are 42 observed precipitation events throughout the year with a maximum daily precipitation of $20 \mathrm{~mm}$ on July 21th, 2018. The soil moisture fluctuation in 2018 is similar to those in 2016 and 2017. There is a freezing period in January-March, in which the soil water content changes in each layer are relatively stable. The March and April belong to the freezing-thawing period. When the frozen soil water gradually melts, the soil below the surface layer is replenished by snowmelt, and the spring snowmelt recharge depth is $160 \mathrm{~cm}$ in 2018 . Consequently, the soil moistures in various layers rise accordingly. April to November is the rainy season. Under the interplay of precipitation-induced infiltration, soil evapotranspiration and vegetation consumption, the soil moisture fluctuates greatly. The shallow soil layer begins to freeze again in December. The layers of intense soil moisture fluctuations are $20 \mathrm{~cm}, 40 \mathrm{~cm}, 80 \mathrm{~cm}, 120 \mathrm{~cm}$, and $160 \mathrm{~cm}$. The soil moisture change at the $200 \mathrm{~cm}$ depth is relatively small, and this layer is only recharged from May 14th to June 6th and on September 7th of 2018.

The DSRs of the PSM forest and the bare sandy land plots are respectively $1.2 \mathrm{~mm}$ and $66.2 \mathrm{~mm}$ in 2018 , as shown in Fig. 11. The results show that the total precipitation in 2018 exceeds the average annual precipitation. Multiple precipitations before the growing season of PSM replenish the deep soil layer moisture. The results show that in 2018, there are two precipitation replenishment processes for DSR, one is the freeze-thaw season from May to June, and the second is the precipitation process in October. The latter is caused by intensive precipitation, which replenishes the entire soil layer.

\subsection{Soil moisture infiltration rate comparison during different seasons}

The soil moisture recharge sources in the experimental area are spring snowmelt and summer precipitation. According to Fig. 5, we can clearly see that the soil water recharge in different seasons varies, especially at the end of winter season and in the summer rainy season. The amount of spring precipitation in this study site is small, and snowmelt moisture is the main water source during the spring season. The germination process of vegetation or seeds in the Mu Us sandy land mainly depends on the water source of accumulated snowfall in winter. With the surface soil temperature increasing, the surface ice gradually melts and infiltrates to deeper soil layer. As shown in Fig. 12(A-B), this study chooses two typical processes for comparison: the snowmelt soil moisture recharge from February 26th to March 27th

Page 9/23 
of 2016, and the precipitation recharge from July 3rd to 12th of 2016. During the process of snowmelt infiltration, the soil wetting front moves slowly downward, as shown in Fig. 12(A). It takes 2 days and 7 hours for the wetting point to reach the $60 \mathrm{~cm}$ depth soil layer, but for the summer precipitation-induced infiltration, it takes only 1 day for the wetting front to reach the $60 \mathrm{~cm}$ depth soil layer.

The soil moisture recharge due to February 26th to March 27th snowmelt in 2016 lasts for 29 days, and the soil moisture recharge depth can reach $160 \mathrm{~cm}$ depth. The soil moisture at $200 \mathrm{~cm}$ depth does not show any noticeable change, suggesting that DSR has not been generated yet. The start time of the moisture recharge is set at the moment when the soil moisture content starts to increase. The end time of the moisture recharge is set at the moment when the soil moisture content reaches its maximum. These two moisture infiltration processes are shown in Fig. 12. There are many factors affecting the rate of precipitation-induced infiltration. A model that does not adequately consider the most relevant factors can certainly leads to erroneous simulation results. In the future, the knowledge gap between the experimental measurement results and the corresponding model simulation should be filled.

\subsection{Recharge intensity of different soil layer infiltration}

In a controlled laboratory experiment, one may calculate the precipitation infiltrating into a specific soil layer according to the soil characteristics with a proper mathematical model. In the natural environment, however, there are too many factors affecting the infiltration process, such as temperature and air humidity, wind speed, surface soil moisture, soil heterogeneity, etc. In this study, we will compute the replenishment of each soil layer by analyzing the precipitationinduced wetting point to find the minimum precipitation for infiltration to reach each individual layer, according to the results of our field test.

During the three-year in-situ observation period, there were 394 observable precipitation events in total. According to the soil moisture fluctuation data recorded by the soil moisture probe, there are 294 precipitation events that have infiltrated into the soil layer below $200 \mathrm{~cm}$ depth.

Table 2

Precipitation produced moisture increase signal and corresponding minimum precipitation (data from 20162018).

\begin{tabular}{|lll|}
\hline Soil layer depths & $\begin{array}{l}\text { Sum of soil moisture increase signals } \\
\text { on each soil layer }\end{array}$ & Corresponding minimum precipitation intensity \\
\hline $20 \mathrm{~cm}$ & 74 & $2.6 \mathrm{~mm} / \mathrm{d}$ \\
\hline $40 \mathrm{~cm}$ & 46 & $3.2 \mathrm{~mm} / \mathrm{d}$ \\
\hline $80 \mathrm{~cm}$ & 32 & $3.4 \mathrm{~mm} / \mathrm{d}$ \\
\hline $120 \mathrm{~cm}$ & 16 & $8.2 \mathrm{~mm} / \mathrm{d}$ \\
\hline $160 \mathrm{~cm}$ & 16 & $10.2 \mathrm{~mm} / \mathrm{d}$ \\
\hline $200 \mathrm{~cm}$ & 10 & $13.2 \mathrm{~mm} / \mathrm{d}$ \\
\hline
\end{tabular}

Infiltration results in elevated soil moisture content. Each time when infiltration reaches a designated depth, it leaves a crest signal of soil water content. Based on the comparison between the time of crest signals and the time of precipitations, the minimum precipitation amount can be determined by the crest signals at different soil depths. Antecedent soil moisture conditions also affect infiltration depth, shallow soil moisture in the semi-arid sandy land will soon return to a relatively dry state because of evapotranspiration. This research describes the general state of soil moisture fluctuations in the experimental area after precipitation. Statistics of precipitation data from 2016 to 2018 and 
fluctuations in soil moisture content in each layer are shown in Table 2, which demonstrates that for infiltration to reach the soil layers at depths of $20 \mathrm{~cm}, 40 \mathrm{~cm}, 80 \mathrm{~cm}, 120 \mathrm{~cm}, 160 \mathrm{~cm}$, and $200 \mathrm{~cm}$, the required daily minimum precipitation intensities are $2.6 \mathrm{~mm}, 3.2 \mathrm{~mm}, 3.4 \mathrm{~mm}, 8.2 \mathrm{~mm}, 8.2 \mathrm{~mm}$, and $13.2 \mathrm{~mm}$, respectively. Infiltration depth and precipitation are not linearly related. This suggests that in the Mu Us sandy land, infiltration will cease to exist when the daily precipitation is less than $2.6 \mathrm{~mm}$, and DSR may be detected only when the daily precipitation becomes greater than $13.2 \mathrm{~mm}$. However, according to the three-year in-situ experimental record, one can see that for some precipitation events whose daily intensities are greater than $13.2 \mathrm{~mm}$, there are no corresponding DSR events detected. Such evidence shows that the precipitation is not the only factor controlling DSR. Besides the precipitation intensity, other factors may also be relevant. Further research is needed to understand those factors impacting the soil moisture dynamics and DSR. One should note that the above infiltration depth is not based on mathematical calculations, but on the basis of the soil moisture fluctuation data monitored by the soil moisture probe at the experimental site.

\subsection{Redistribution of precipitation in the PSM forest}

Figure 5 shows that during the seasonal frozen-soil period, soil moisture is relatively stable. The monthly average values for soil moistures of different soil layers in January and December of 2016 are used as the start and end soil moisture values. Although the precipitation amount varies from 2016 to 2018, other environmental factors in this area are basically the same, and soil moistures are similar. To figure out the PSM water balance from 2016 to 2018, one has:

P-DSR-ET $=\delta W(2)$

where $\mathrm{P}$ is precipitation, ET is evapotranspiration, and $\delta \mathrm{W}$ is the whole $200 \mathrm{~cm}$ soil layer moisture change. Runoff is not included in above water balance equation because it does not occur during the experiment. As precipitation, DSR, and $\delta W$ can be accurately measured, ET can be calculated by above equation.

Table 3 shows the precipitation, DSR, $\delta$ W, and the computed ET for 2016-2018. Based on Table 2, one can see that precipitation has played a role in regulating and replenishing soil moisture for both shallow and deep soil layers. For the shallow soil layer, evapotranspiration in the dry year (like 2018) consumes stored water from previous wet year (2016), but in the wet year (like 2016), precipitation recharges the shallow soil layer. The recorded DSR values in 2016-2018 are very small, as compared to other terms in above Eq. (2), indicating that under the existing vegetation cover and rainfed conditions, the precipitation is barely able to support the shallow groundwater ecosystems, and has almost no capacity to provide recharge for groundwater reservoir in the region. However, in the bare sandy plot, the precipitation indeed can provide moderate recharge for groundwater reservoir, as reflected in the sizable annual DSR values there. In semiarid regions such as the Mu Us sandy land, precipitation varies considerably every year, and the year of 2016 may not be representative of the long-term average behavior of DSR in this region as the precipitation of this year is higher than the average annual precipitation of $400 \mathrm{~mm}$. One can see that in different years, vegetation water consumption patterns are different, and evapotranspiration decreases in dry year and increases in wet year. One common feature among wet and dry years is that precipitation-induced infiltrated water is trapped in shallow soil layers and then consumed by PSM. To understand the long-term behavior of DSR and soil moisture dynamics in the semiarid regions such as the Mu Us Sandy land, one must carry out a multi-year (preferably a decade long) experiment.

As shown in Table 3, comparing the PSM plot and the bare soil land (BSL) plot, it can be found that the ET is $466.94 \mathrm{~mm}$ and the DSR is $1.4 \mathrm{~mm}$ for the PSM plot in 2016; while the ET is $137.13 \mathrm{~mm}$ and the DSR is $237.6 \mathrm{~mm}$ for the BSL plotin 2016. From this observation one can conclude that due to vegetation reconstruction, the DSR is significantly reduced and the ET is significantly increased in this year. 2018 was a relatively dry year, with precipitation of $239.8 \mathrm{~mm}$ in 2018 . Due to the decrease in precipitation, the DSR has decreased in both plots. The DSR in the PSM plot is $1.2 \mathrm{~mm}$ and the BSL plot DSR is 55.2 mm, which is significantly lower than the ET and DSR in 2016.

Page $11 / 23$ 
Table 3

Water distribution of the rainfed PSM and bare sandy plot

\begin{tabular}{|c|c|c|c|c|c|}
\hline Year & Plot & Precipitation & DSR & $\delta W$ & ET \\
\hline \multirow[t]{2}{*}{2016} & PSM & $506.4 \mathrm{~mm}$ & $1.4 \mathrm{~mm}$ & $38.06 \mathrm{~mm}$ & $466.94 \mathrm{~mm}$ \\
\hline & BSL & $506.4 \mathrm{~mm}$ & $273.6 \mathrm{~mm}$ & $95.67 \mathrm{~mm}$ & $137.13 \mathrm{~mm}$ \\
\hline \multirow[t]{2}{*}{2017} & PSM & $309 \mathrm{~mm}$ & $0.4 \mathrm{~mm}$ & $-16.00 \mathrm{~mm}$ & $324.60 \mathrm{~mm}$ \\
\hline & BSL & 309 mm & $67.7 \mathrm{~mm}$ & $61.89 \mathrm{~mm}$ & $179.41 \mathrm{~mm}$ \\
\hline \multirow[t]{2}{*}{2018} & PSM & $239.8 \mathrm{~mm}$ & $1.2 \mathrm{~mm}$ & $54.75 \mathrm{~mm}$ & $183.85 \mathrm{~mm}$ \\
\hline & BSL & $239.8 \mathrm{~mm}$ & $55.2 \mathrm{~mm}$ & $96.8 \mathrm{~mm}$ & $87.8 \mathrm{~mm}$ \\
\hline
\end{tabular}

\section{Discussion}

In semi-arid areas, the main limiting factor for ecosystems is available water resources (Gao et al., 2014;Skarpe, 1991). Therefore, the key to understand the vegetation ecosystem in semi-arid areas is to study the supply of water resources (Cheng et al., 2018;Cheng et al., 2017b). The PSM has been in existence in the study area for more than 30 years, so the purpose of this study is to find out whether there is sufficient water resource available in the region to support vegetation ecosystem, through the measurement of deep soil water recharge (or DSR). The "sustainable" growth of plants in this study means that water resource from precipitation can meet the growth needs of PSM, and can still have an excess amount of water to replenish deep soil layer (to recharge the deep groundwater system beyond the root zones of plants). In this study, the soil moisture distribution of PSM is studied using a newly designed lysimeter to see whether the soil layer below the root layer could produce DSR or not. PSM has become the preferred afforestation tree species in arid and semi-arid aeolian sand regions in western China due to its characteristics of drought resistance, cold resistance, rapid growth rate, windproof and sand fixation. Previous studies on PSM forest mainly focused on the construction and management of PSM forest, its decay mechanism and adaptability. The impact of PSM forest on soil moisture dynamics and DSR is much less studied.

Lysimeter has been developed for hundreds of years and is widely used in the field of water balance research (Liu et al., 2002; López-Urrea et al., 2006;Boast and Robertson, 1982). The conventional lysimeter has a size limitation, and is ineffective in measuring trees and other large plants (Fritschen et al., 1977). The new lysimeter solves the shortcomings of conventional instruments that cannot be observed in situ due to the high cost. Conventional lysimeter need to excavate soil and transplant trees. Due to the large root system, conventional instruments cannot observe tall trees. This study uses a newly designed lysimeter to measure the deep soil moisture infiltration for water balance investigation (Cheng et al., 2017b). From the field observation results of 2016 to 2018, In Mu Us sandy land, there is no direct relationship between annual precipitation and the amount of penetration or DSR, DSR is related to heavy precipitation, which can be inferred that it is not feasible to use an infiltration coefficient to estimate the DSR. In semi-arid region, DSR is closely related to vegetation coverage, precipitation patterns and other factors.

Vegetation depends on precipitation, and roots are concentrated in shallow soil layers. Measuring the water absorption of topsoil and interception of the canopy are complicated processes and often involves a great degree of uncertainty. This research, however, regards the canopy and topsoil as an integrated entity. And by measuring the amount of water entering the entity (precipitation) and the amount of water leaving the entity (deep soil recharge), one may conduct a water balance computation to calculate the amount of overall evapotranspiration. 
This study monitors the distribution of soil moisture of PSM forest under the rainfed conditions in a three year period (2016-2018), and try to understand whether the soil moisture is sufficient (or sustainable) under existing precipitation conditions. One should be cautious that the three-year (2016-2018) soil moisture measurements presented in this study may not be representative of the long-term ecohydrological process in the region. Therefore, it is necessary to perform long term (such as decades long) observation and analysis in the region to see if the studied species (PSM) can develop sustainably or not over decades as some artificial trees may have life cycles over decades long. Another notable point is that the adaptability of long-lived woody species may not be based solely on water, temperature, light, and soil texture. Despite such limitations, this three-year investigation offers an important step for understanding the soil moisture dynamics of sand-fixing PSM forest in a semi-arid region. Fortunately, these three years (2016-2018) happen to encompass rather dramatically different weather patterns in the region (wet versus dry years), thus this study offers insights on the function of the PSM forest under both wet and dry years.

\section{Conclusions}

The following conclusions can be drawn from this study:

1. PSM can survive in Mu Us Sandy Land and prevent sandy soil erosion even though the precipitation in the area fluctuates over the years.

2. The fine roots of PSM in the Mu Us sandy land are distributed in the shallow soil layer of 0-100 cm depth, and the precipitation-induced infiltration is intercepted and stored in shallow soil layers as well. PSM cannot use the groundwater because of the deep water table ( $8 \mathrm{~m}$ below ground surface) in the study site.

3. The spring snowmelt recharge can reach $160 \mathrm{~cm}$ of depth underneath the PSM forest. The summer precipitationinduced infiltration can result in a limited amount of DSR whose values are respectively $1.4 \mathrm{~mm}, 0.2 \mathrm{~mm}, 1.2 \mathrm{~mm}$ in 2016, 2017 and 2018 underneath the PSM forest.

4. For precipitation-induced infiltration to reach depths of $20 \mathrm{~cm}, 40 \mathrm{~cm}, 80 \mathrm{~cm}, 120 \mathrm{~cm}, 160 \mathrm{~cm}$, and $200 \mathrm{~cm}$ soil layers, the daily precipitation intensities have to be greater than $2.6 \mathrm{~mm}, 3.2 \mathrm{~mm}, 3.4 \mathrm{~mm}, 8.2 \mathrm{~mm}, 8.2 \mathrm{~mm}$, and $13.2 \mathrm{~mm}$, respectively. Infiltration depth and precipitation are not linearly related.

5. In the Mu Us sandy land, the amount of DSR is not related to annual precipitation. The amount of DSR is related to heavy precipitation events, but is not in proportional manner. After the PSM forest is restored, the precipitation moisture is basically absorbed by the vegetation layer, and the deep soil cannot be recharged by precipitation moisture. The growth of PSM is closely affected by the annual precipitation regardless of the wet year (2016) and dry year (2018).

6. PSM adjusts its evapotranspiration in response to different precipitation amounts in 2017-2018.

\section{List Of Abbreviations}

Three North Shelterbelt Program (3NSP)

Pinus sylvestris var. mongolica (PSM)

deep soil recharge (DSR)

evapotranspiration (ET)

\section{Declarations}

Ethics approval and consent to participate: Not applicable

Page 13/23 
Consent for publication: Not applicable

Availability of data and material: All the datas are available from the corresponding author on reasonable request

Competing interests: The authors declare that they have no competing interests

Funding: This study was supported with research grants from the National Nonprofit Institute Research Grant of Chinese Academy of Forestry (grant number CAFYBB2018ZA004), the Fundamental Research Funds for the Central Universities (BLX201814), National Science and Technology Major Project (No. 2017ZX07101004) and the National Natural Science Foundation of China (41771306).

Authors' contributions: Author contributions: C.YB., Y.WB., and Z.HB., conceived the idea; C.YB., J.QO., and W.YQ., conducted the analyses; C.YB., G.FQ., and Y.WB., provided the data; all authors contributed to the writing and revisions.

Acknowledgements: We gratefully acknowledge the Beijing Municipal Education Commission for their financial support through Innovative Transdisciplinary Program "Ecological Restoration Engineering". We thank the Desert Forestry Experimental Center of the Chinese Academy of Forestry for providing the experimental site.

\section{References}

1. Bao G (2015) Mongolian pines (Pinus sylvestris var. mongolica) in the Hulun Buir steppe, China, respond to climate in adjustment to the local water supply. Int J Biometeorol 59:1-10. 10.1007/s00484-013-0767-3

2. Bargués Tobella A, Reese $H$, Almaw A, Bayala J, Malmer A, Laudon H, llstedt UJ W. R. R.: The effect of trees on preferential flow and soil infiltrability in an agroforestry parkland in semiarid Burkina Faso, 50, 3342-3354, 2014

3. Bawa KS, Koh LP, Lee TM, Liu J, Ramakrishnan P, Douglas WY, Zhang Y-p, Raven PH (2010) China, India, and the environment. Science 327:1457-1459

4. Boast C, Robertson T (1982) A "Micro-Lysimeter" Method for Determining Evaporation from Bare Soil: Description and Laboratory Evaluation 1. Soil Sci Soc Am J 46:689-696

5. Bouma J, Dekker LW: A case study on infiltration into dry clay soil I. Morphological observations, Geoderma, 20, 2740, 1978

6. Burgess SS, Adams MA, Turner NC, Ong CK (1998) The redistribution of soil water by tree root systems. Oecologia 115:306-311

7. Cao S, Chen L, Shankman D, Wang C, Wang X, Zhang H (2011) Excessive reliance on afforestation in China's arid and semi-arid regions: lessons in ecological restoration. Earth Sci Rev 104:240-245

8. Cheng Y, Zhan H, Yang W, Dang H, Li W (2017a) Is annual recharge coefficient a valid concept in arid and semi-arid regions? Hydrol Earth Syst Sci 21:5031-5042. 10.5194/hess-21-5031-2017

9. Cheng Y, Zhan H, Yang W, Dang H, Li W (2017b) Is annual recharge coefficient a valid concept in arid and semi-arid regions. Hydrol Earth Syst Sci 21:5031-5042

10. Cheng Y, Li Y, Zhan H, Liang H, Yang W, Zhao Y, Li T (2018) New comparative experiments of different soil types for farmland water conservation in arid regions. Water 10:298

11. Contreras S, Jobbágy EG, Villagra PE, Nosetto MD, Puigdefábregas J (2011) Remote sensing estimates of supplementary water consumption by arid ecosystems of central Argentina. J Hydrol 397:10-22. https://doi.org/10.1016/j.jhydrol.2010.11.014

12. Fritschen LJ, Hsia J, Doraiswamy P (1977) Evapotranspiration of a Douglas fir determined with a weighing lysimeter. Water Resour Res 13:145-148

Page 14/23 
13. Gao Y, Zhu X, Yu G, He N, Wang Q, Tian J (2014) Water use efficiency threshold for terrestrial ecosystem carbon sequestration in China under afforestation. Agric For Meteorol 195:32-37

14. García Chevesich P, Neary DG, Scott DF, Benyon RG, Reyna T: Forest management and the impact on water resources: a review of 13 countries, UNESCO Publishing, 2017

15. Gerten D, Schaphoff S, Haberlandt U, Lucht W, Sitch S (2004) Terrestrial vegetation and water balance-hydrological evaluation of a dynamic global vegetation model. J Hydrol 286:249-270.

https://doi.org/10.1016/j.jhydrol.2003.09.029

16. Hu YL, Zeng DH, Fan ZP, Chen GS, Zhao Q, Pepper D (2008) Changes in ecosystem carbon stocks following grassland afforestation of semiarid sandy soil in the southeastern Keerqin Sandy Lands, China. J Arid Environ 72:2193-2200. https://doi.org/10.1016/j.jaridenv.2008.07.007

17. $10.1007 /$ s12665-012-2023-2

Li W, Yan M, Qingfeng Z, Xingchang Z: Groundwater use by plants in a semi-arid coal-mining area at the Mu Us Desert frontier, Environmental Earth Sciences, 69, 1015-1024, 10.1007/s12665-012-2023-2, 2013a

18. Li X-R, Xiao H-L, Zhang J-G, Wang X-P (2004) Long-Term Ecosystem Effects of Sand-Binding Vegetation in the Tengger Desert, Northern China. Restor Ecol 12:376-390. 10.1111/j.1061-2971.2004.00313.x

19. Li X, Zhang Z, Huang L, Wang X (2013b) Review of the ecohydrological processes and feedback mechanisms controlling sand-binding vegetation systems in sandy desert regions of China. Chin Sci Bull 58:1483-1496. $10.1007 / \mathrm{s} 11434-012-5662-5$

20. Liu C, Zhang X, Zhang Y (2002) Determination of daily evaporation and evapotranspiration of winter wheat and maize by large-scale weighing lysimeter and micro-lysimeter. Agric For Meteorol 111:109-120

21. Liu Q, Yasufuku N, Miao J, Ren J (2014) An approach for quick estimation of maximum height of capillary rise. Soils Found 54:1241-1245

22. López-Urrea R, de Santa Olalla FM, Fabeiro C, Moratalla A (2006) Testing evapotranspiration equations using lysimeter observations in a semiarid climate. Agricultural water management 85:15-26

23. Menon S, Hansen J, Nazarenko L, Luo Y (2002) Climate effects of black carbon aerosols in China and India. Science 297:2250-2253

24. Reynolds JF, Smith DMS, Lambin EF, Turner B, Mortimore M, Batterbury SP, Downing TE, Dowlatabadi H, Fernández RJ, Herrick JE J. s.: Global desertification: building a science for dryland development, 316, 847-851, 2007

25. Runnström MC (2000) Is Northern China Winning the Battle against Desertification? AMBIO: A Journal of the Human Environment 29:468-476. 10.1579/0044-7447-29.8.468

26. Runnström MC (2003) Rangeland development of the Mu Us Sandy Land in semiarid China: an analysis using Landsat and NOAA remote sensing data. Land Degradation Development 14:189-202. 10.1002/ldr.545

27. Sharma P, Sharma P: Ecology and environment, Rastogi Publications, 2005

28. Skarpe C (1991) Spatial patterns and dynamics of woody vegetation in an arid savanna. J Veg Sci 2:565-572

29. Song L, Zhu J, Li M, Yu ZJT: Water utilization of Pinus sylvestris var. mongolica in a sparse wood grassland in the semiarid sandy region of Northeast China, 28, 971-982, 2014

30. Song L, Zhu J, Li M, Zhang J, Lv LJ A. w. m.: Sources of water used by Pinus sylvestris var. mongolica trees based on stable isotope measurements in a semiarid sandy region of Northeast China, 164, 281-290, 2016

31. Sun W, Song X, Mu X, Gao P, Wang F, Zhao G (2015) Spatiotemporal vegetation cover variations associated with climate change and ecological restoration in the Loess Plateau. Agric For Meteorol 209:87-99

32. Wang F, Pan X, Wang D, Shen C, Lu Q (2013) Combating desertification in China: past, present and future. Land Use Policy 31:311-313 
33. Wang X, Zhang C, Hasi E, Dong Z: Has the Three Norths Forest Shelterbelt Program solved the desertification and dust storm problems in arid and semiarid China?, Journal of Arid Environments, 74, 13-22, 2010a

34. Wang XM, Zhang CX, Hasi E, Dong ZB (2010b) Has the Three Norths Forest Shelterbelt Program solved the desertification and dust storm problems in arid and semiarid China? J Arid Environ 74:13-22.

https://doi.org/10.1016/j.jaridenv.2009.08.001

35. Wu B, Han H, He J, Zhang J, Cui L, Jia Z, Yang W (2014) Field-Specific Calibration and Evaluation of ECH 20 EC-5 Sensor for Sandy Soils. Soil Sci Soc Am J 78:70-78

36. Wu Z, Wu J, Liu J, He B, Lei T, Wang Q (2013) Increasing terrestrial vegetation activity of ecological restoration program in the Beijing-Tianjin Sand Source Region of China. Ecol Eng 52:37-50

37. Young A: Agroforestry for soil conservation, 04; S599. 9. T76, Y68., CAB international Wallingford, UK, 1989

38. Zeng D, Hu Y, Chang S, Fan ZJP, and soil: Land cover change effects on soil chemical and biological properties after planting Mongolian pine (Pinus sylvestris var. mongolica) in sandy lands in Keerqin, northeastern China, 317, 121133,2009

39. Zhao D, Li F, Wang R, Yang Q, Ni HJ J. o. s., and sediments: Effect of soil sealing on the microbial biomass, $N$ transformation and related enzyme activities at various depths of soils in urban area of Beijing, China, 12, 519-530, 2012

40. Zheng X, Zhu J, Yan Q, Song LJAWM (2012) Effects of land use changes on the groundwater table and the decline of Pinus sylvestris var. mongolica plantations in southern Horqin Sandy Land. Northeast China 109:94-106

41. Zhu J, Kang H, Tan H, Xu M (2006) Effects of drought stresses induced by polyethylene glycol on germination of Pinus sylvestris var. mongolica seeds from natural and plantation forests on sandy land. Journal of Forest Research 11:319-328

\section{Figures}
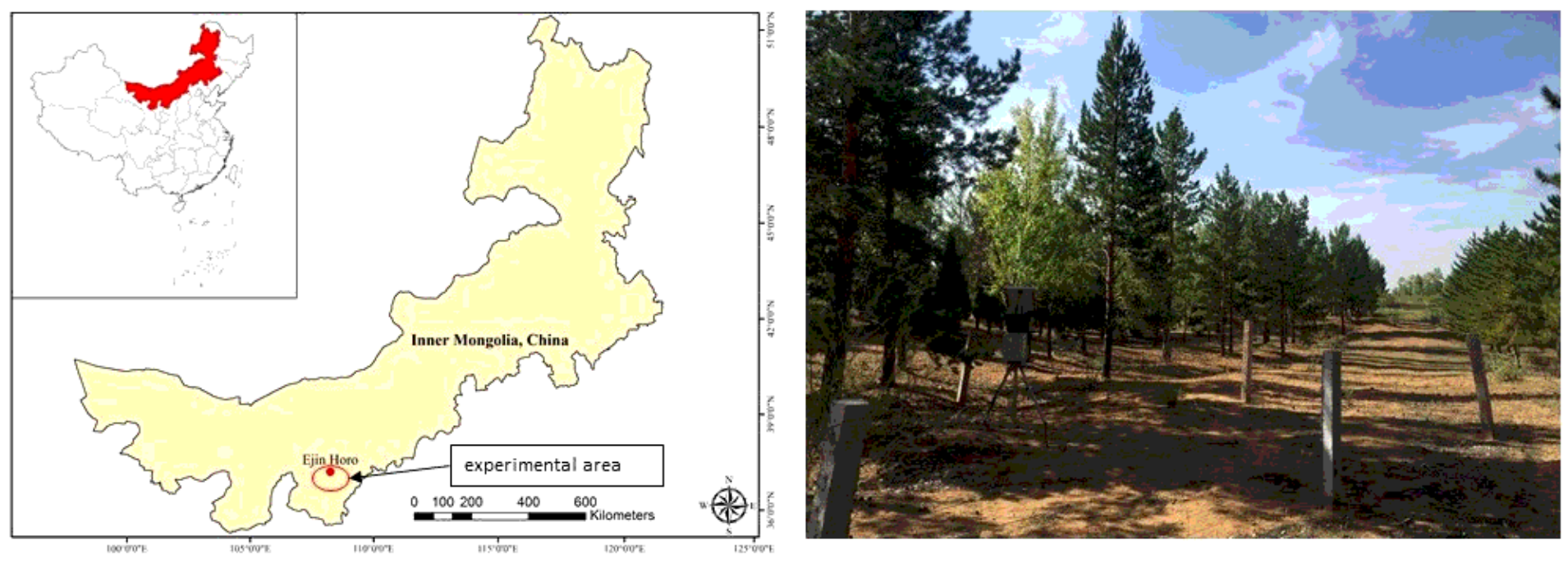

\section{Figure 1}

Geographic location of the experimental area and study site. Note: The designations employed and the presentation of the material on this map do not imply the expression of any opinion whatsoever on the part of Research Square concerning the legal status of any country, territory, city or area or of its authorities, or concerning the delimitation of its frontiers or boundaries. This map has been provided by the authors. 


\section{Precipitation}

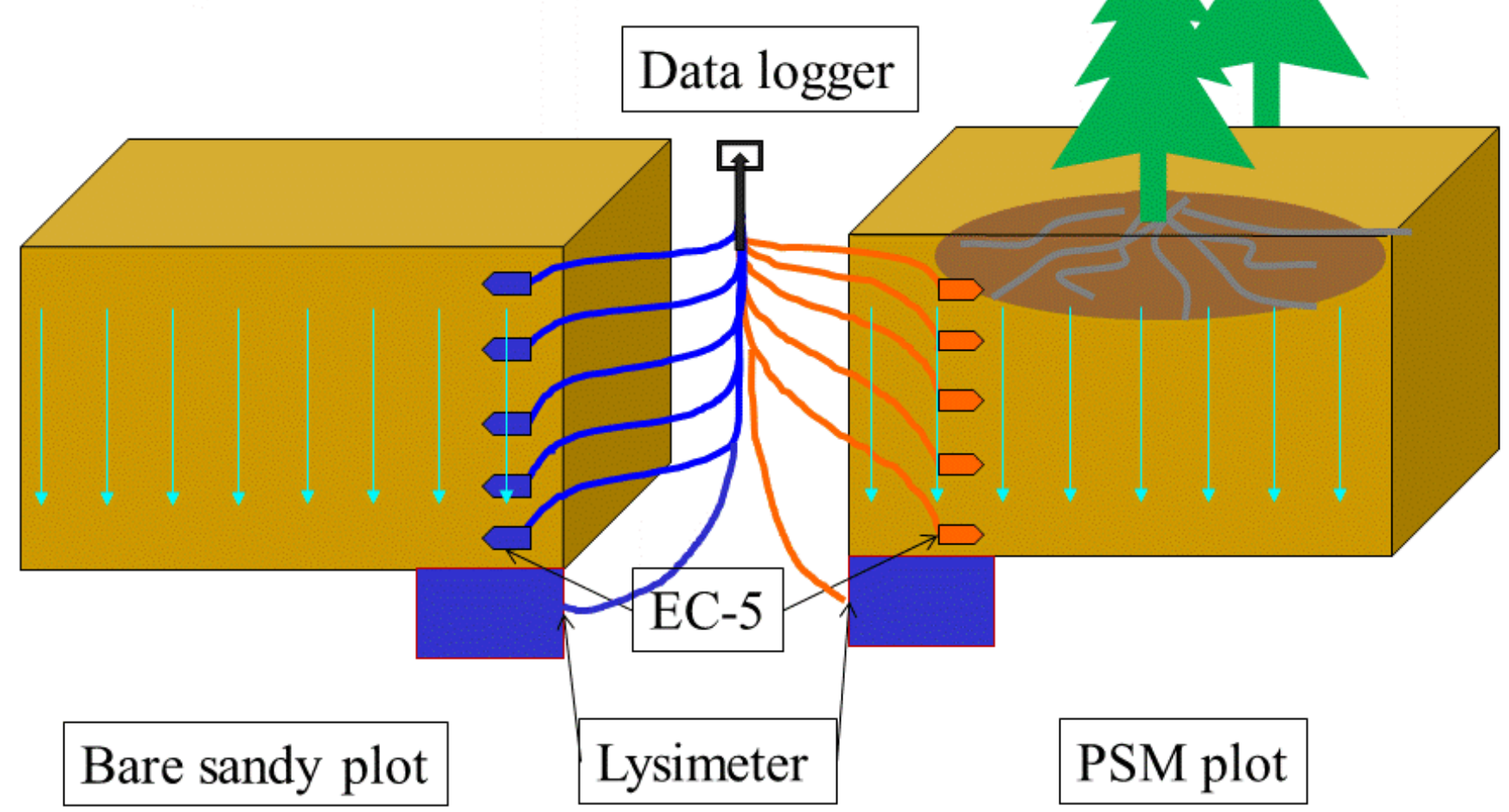

Figure 2

Experimental plot setup. 

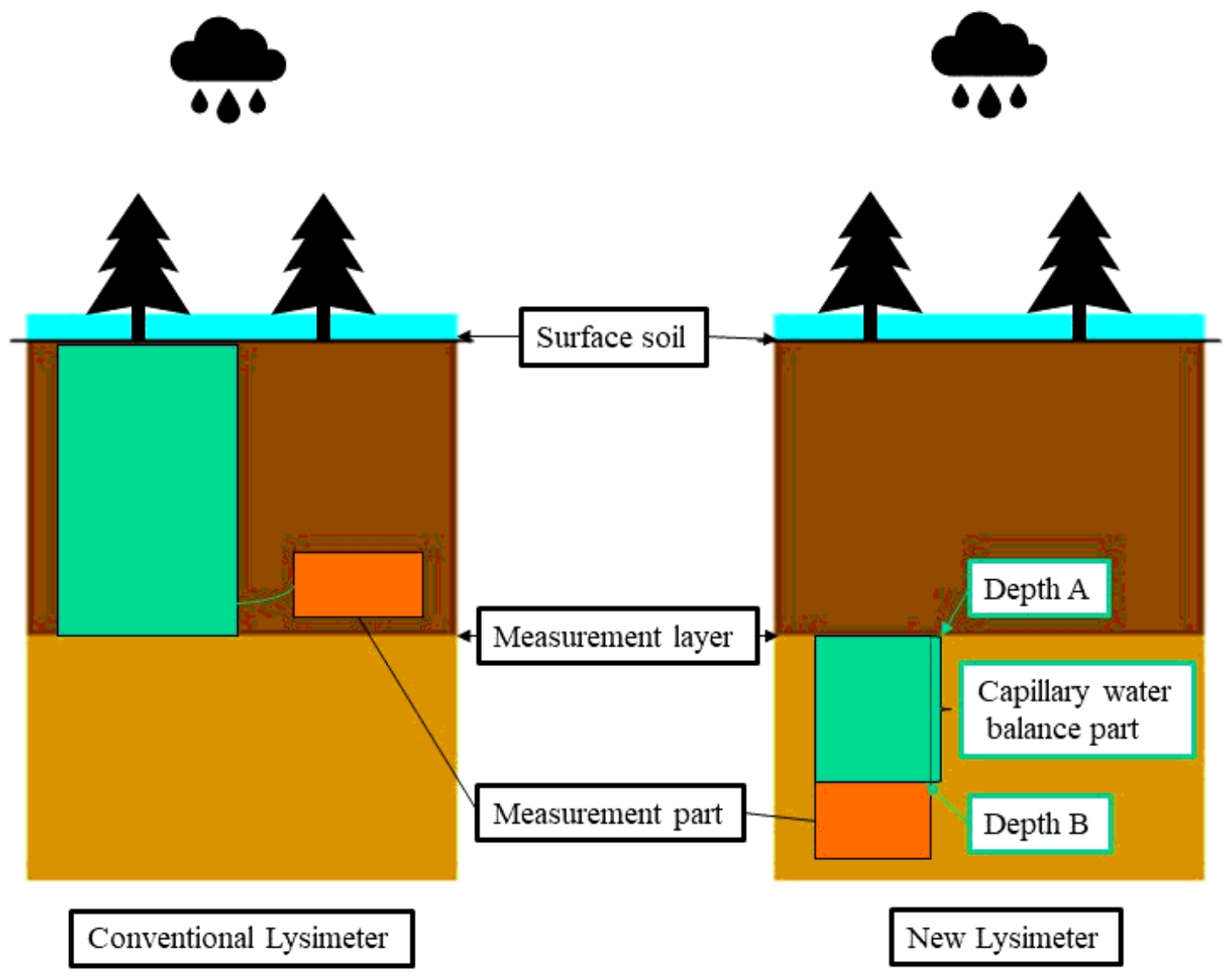

Figure 3

The schematic plot of a new lysimeter (on the right) with respect to the conventional lysimeter (on the left). 


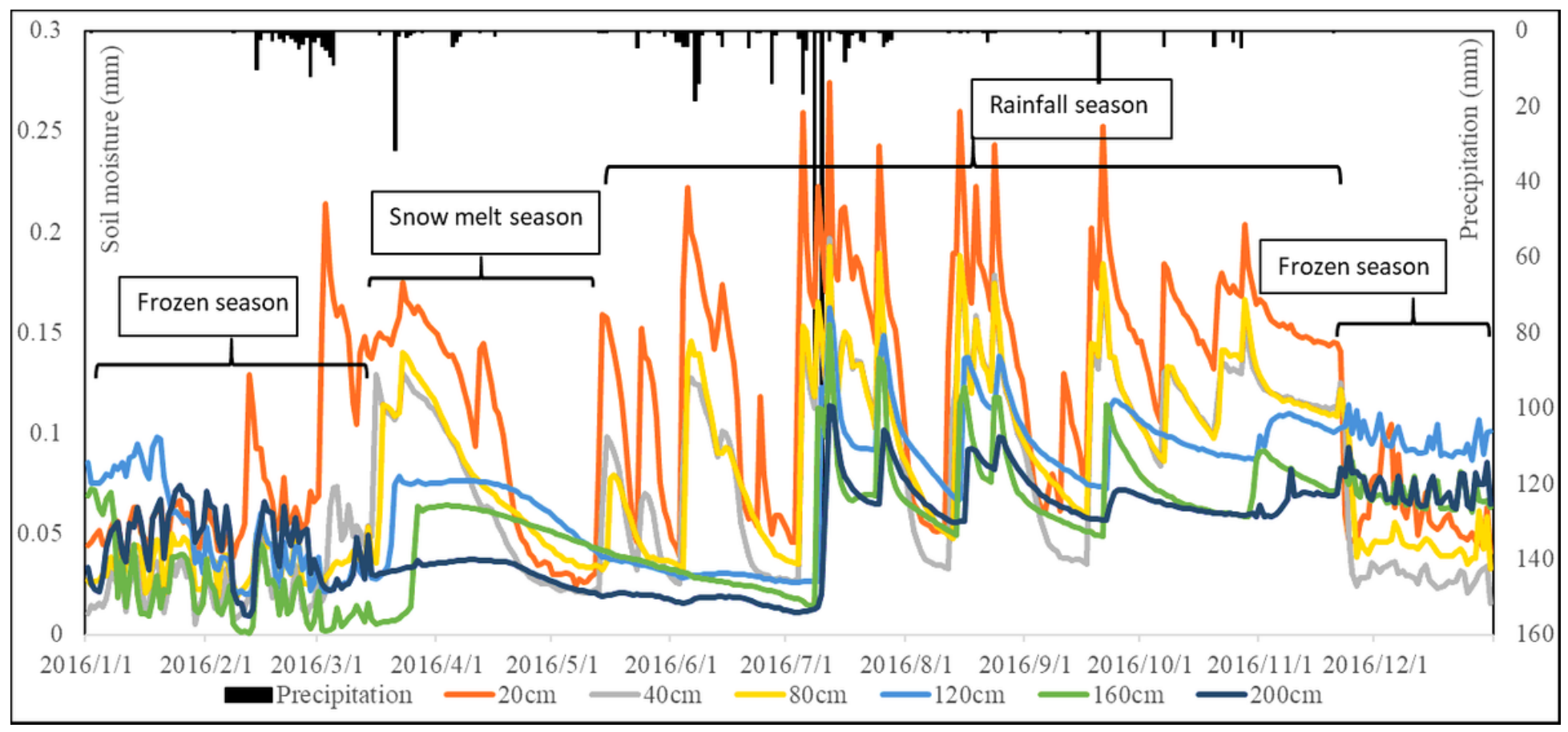

Figure 4

Annual precipitation and soil moisture of each layers in 2016.

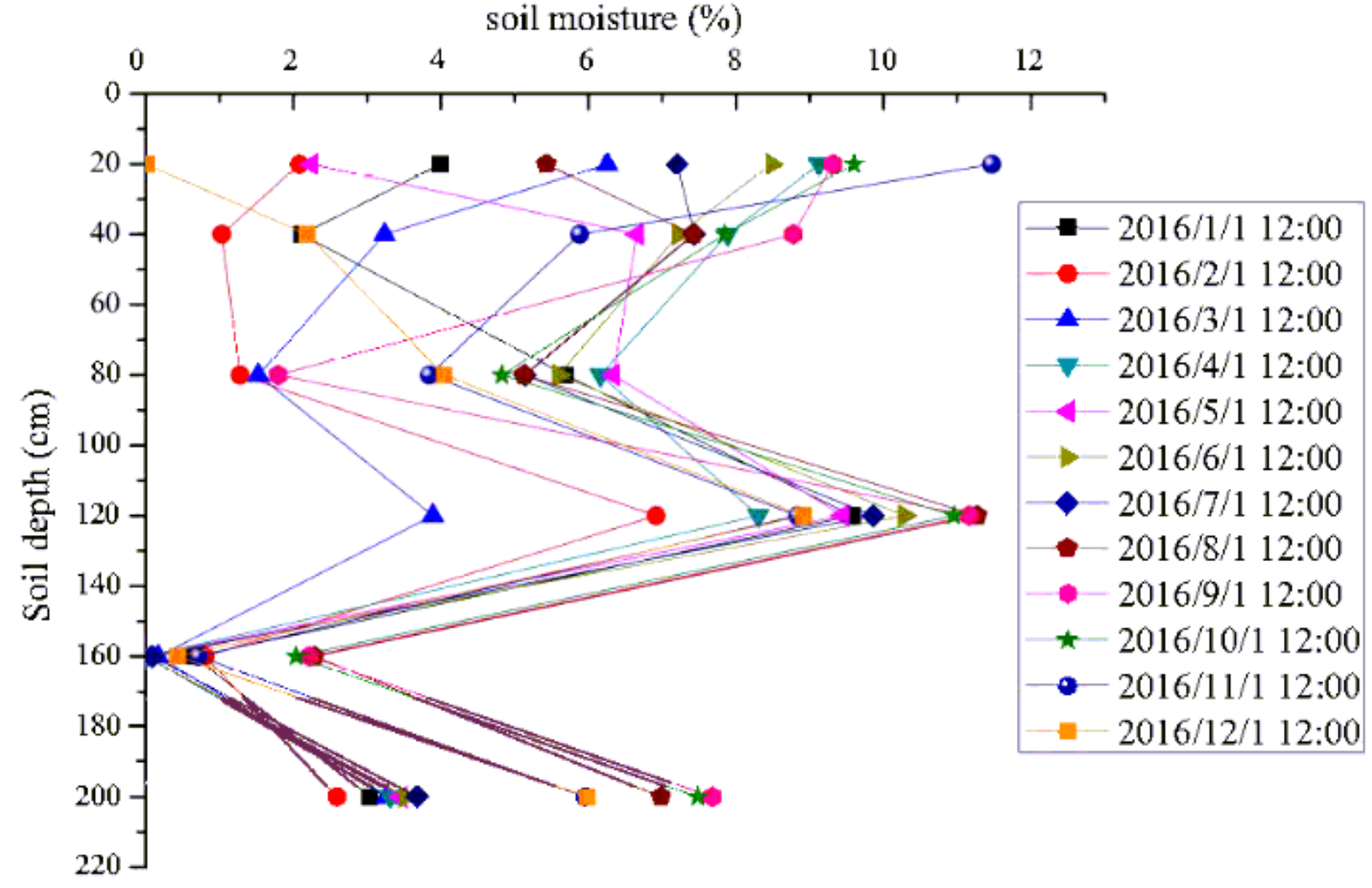

Figure 5

Month soil moisture changes of soil layers at different depths in 2016. 


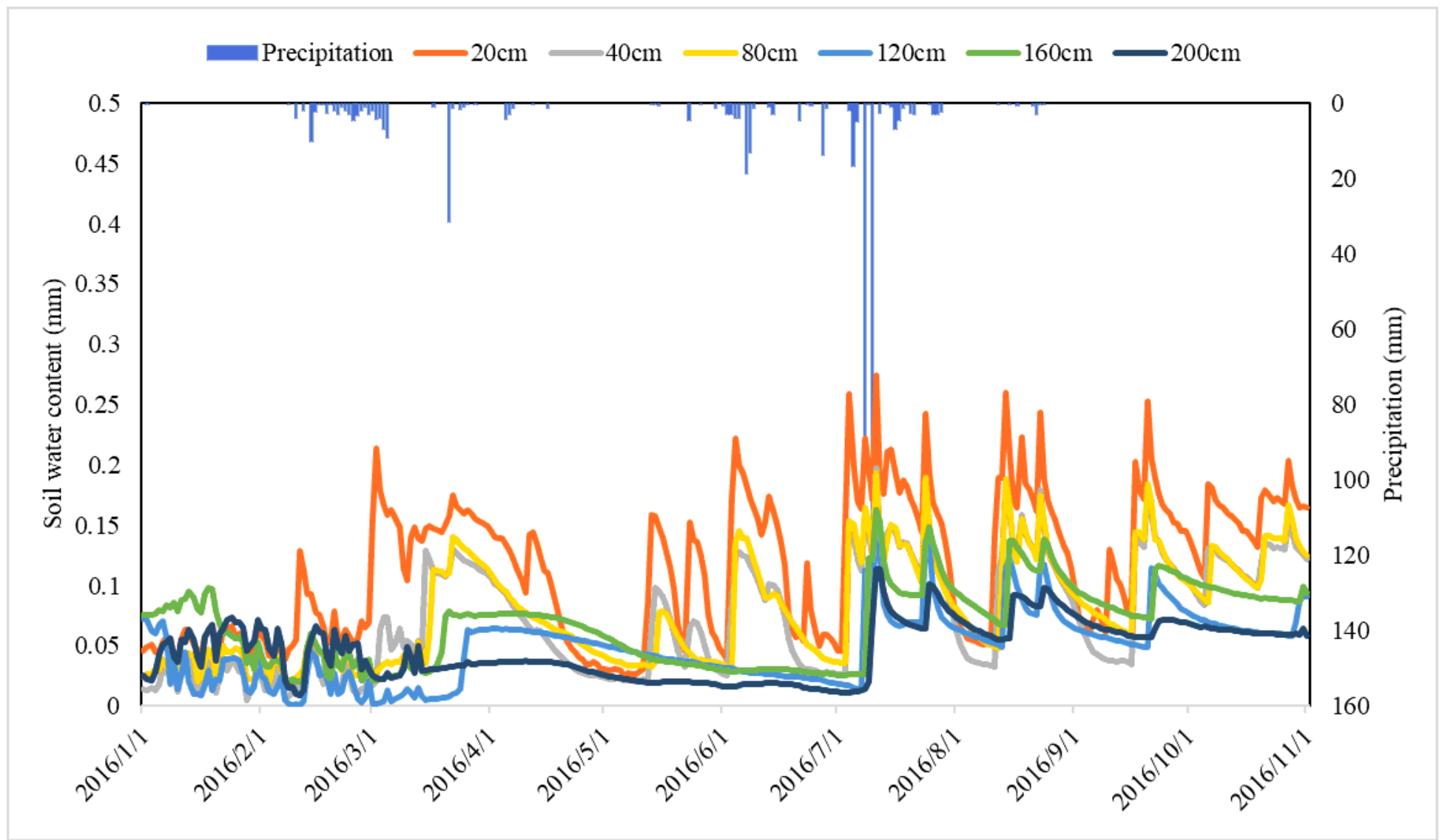

Figure 6

The relationship between precipitation and soil moisture distribution in 2016

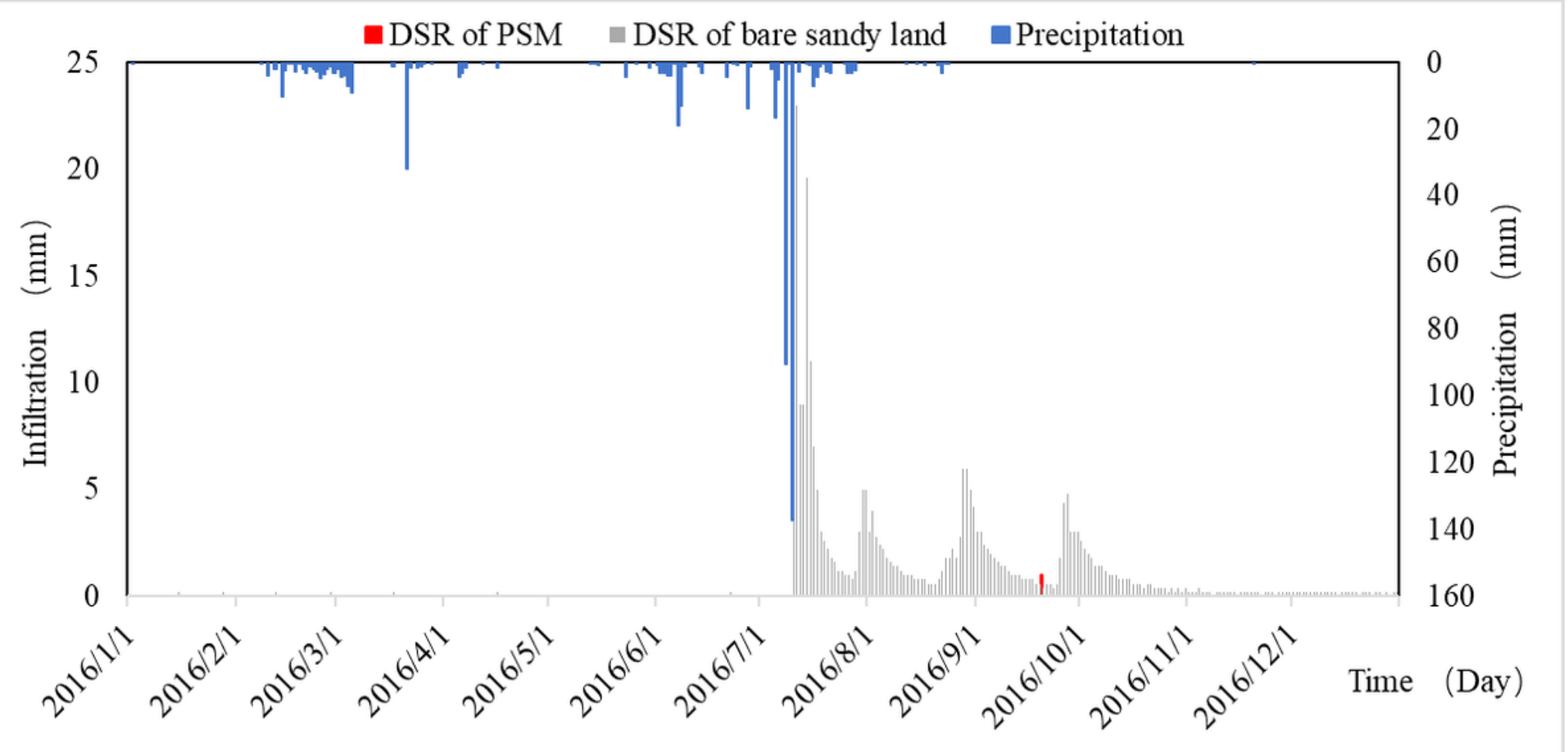

Figure 7

Soil moisture and DSR dynamic change in 2016. 


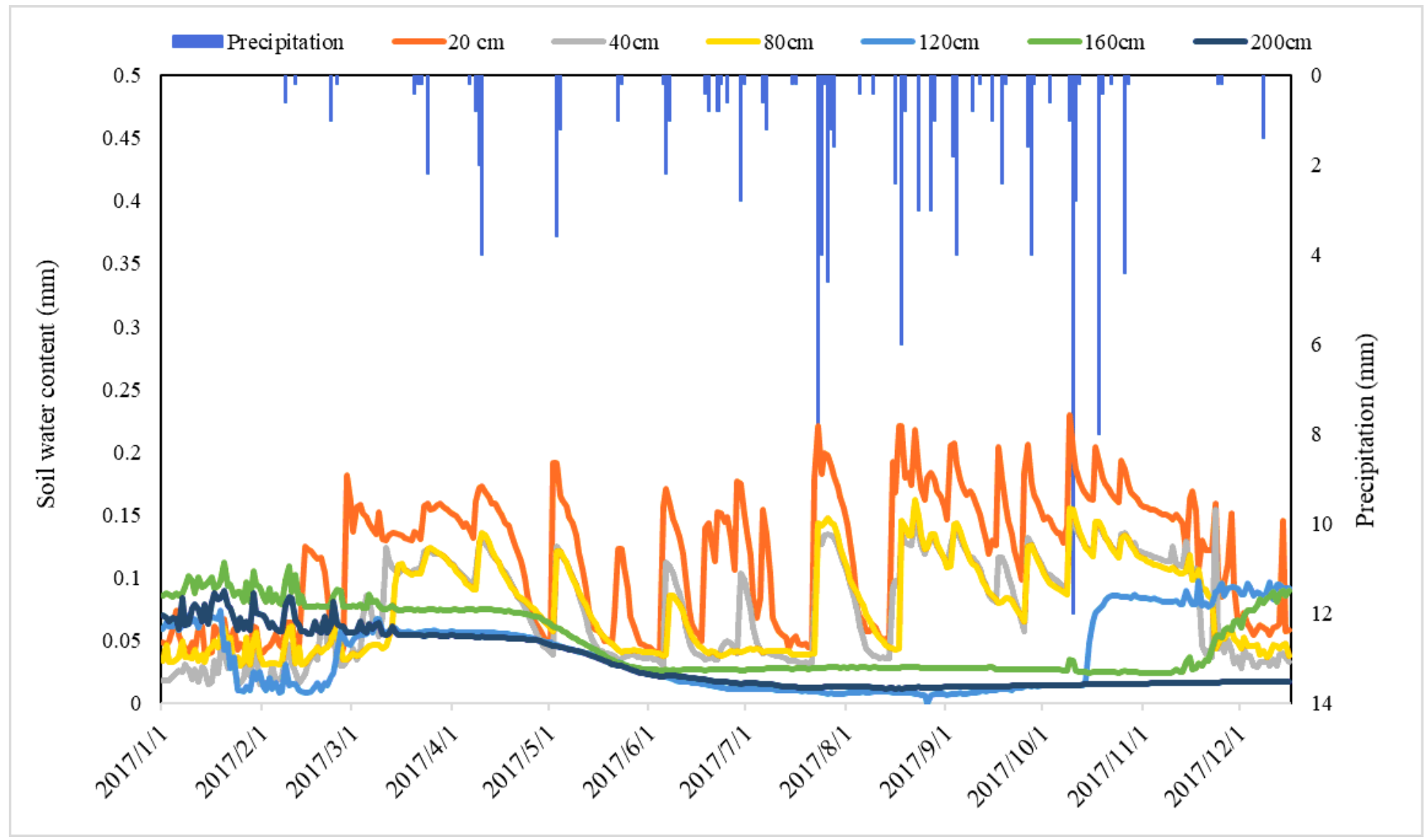

Figure 8

The relationship between precipitation and soil moisture distribution in 2017.

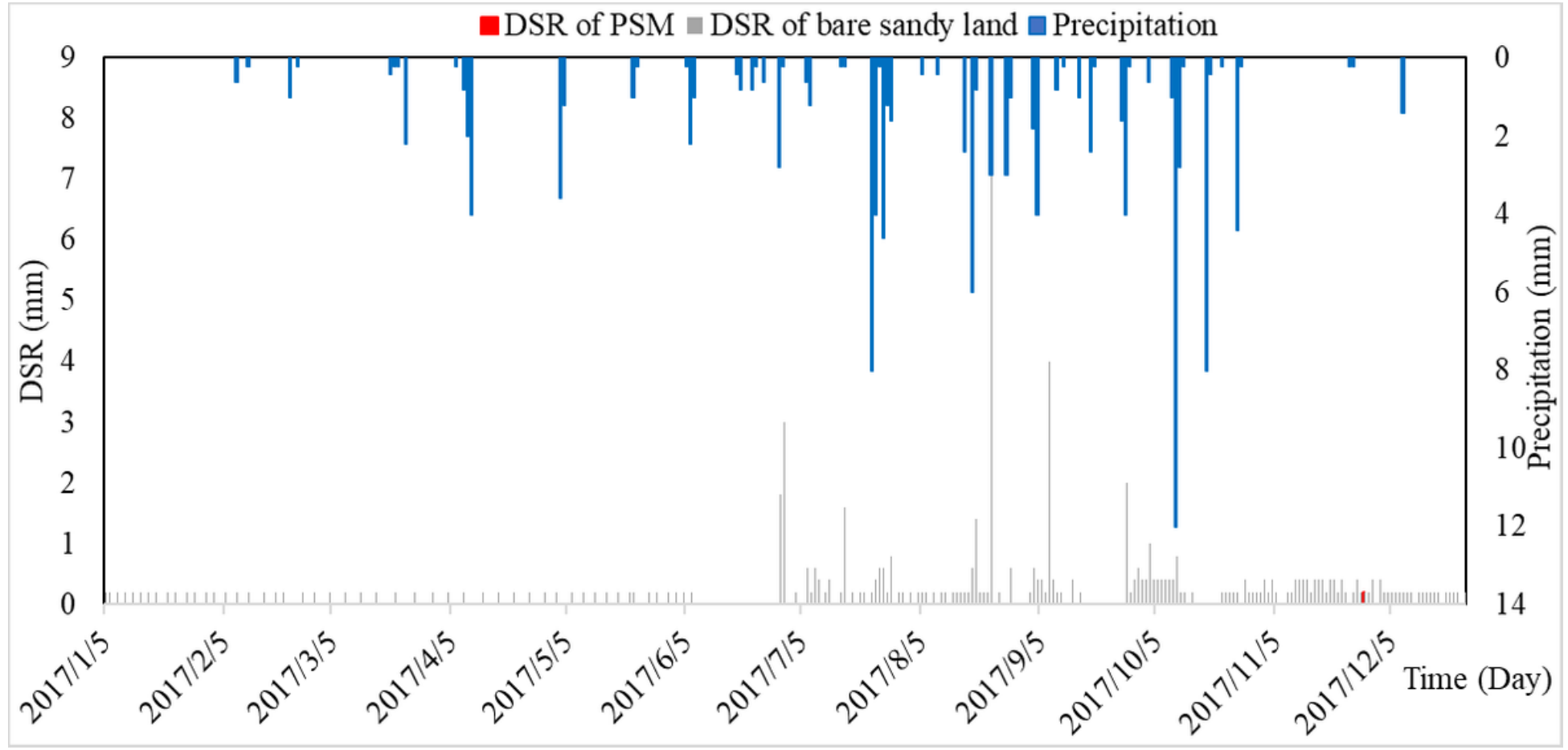

Figure 9

Soil moisture and DSR dynamic change in 2017. 


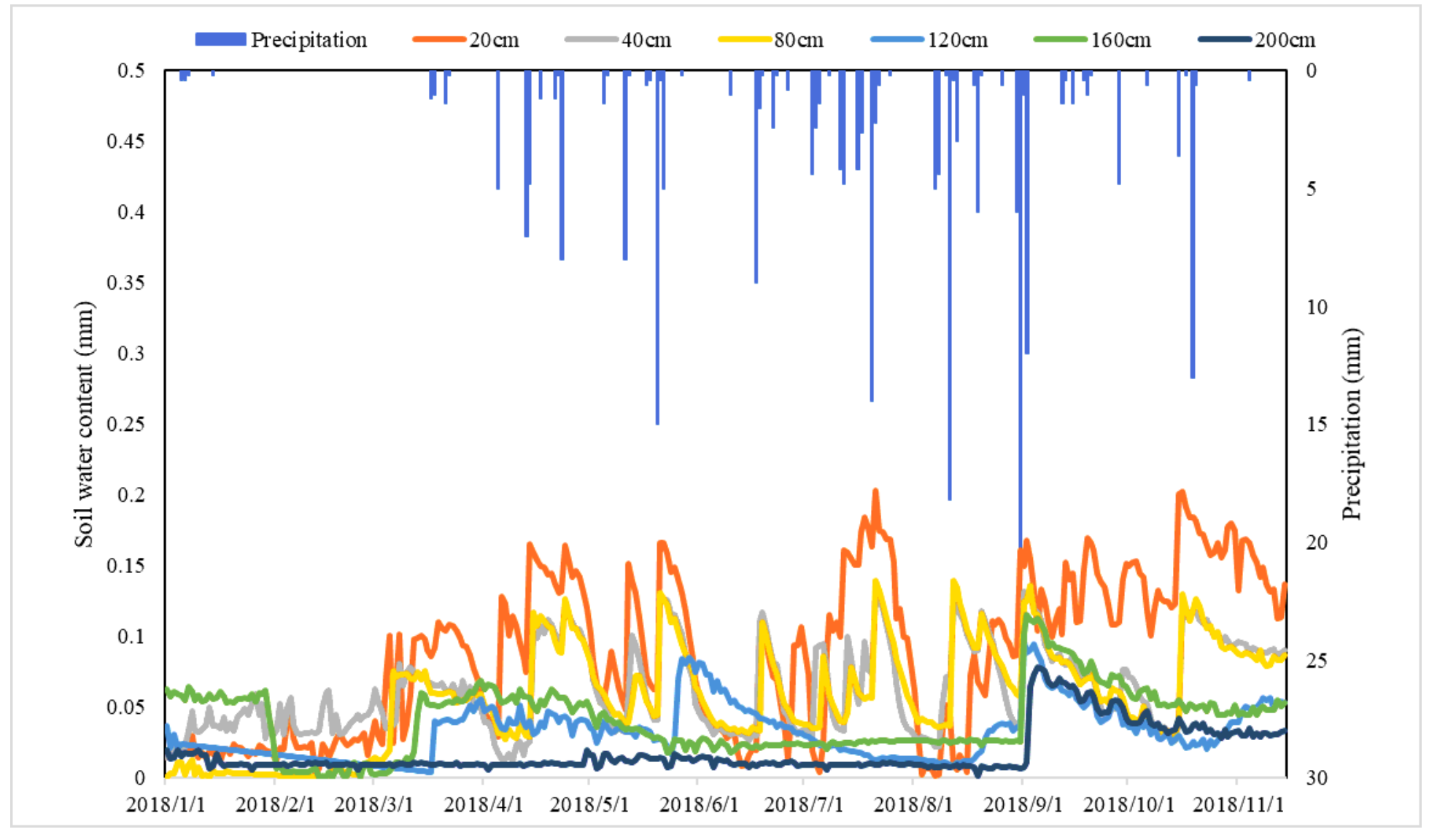

Figure 10

The relationship between precipitation and soil moisture distribution in 2018 .

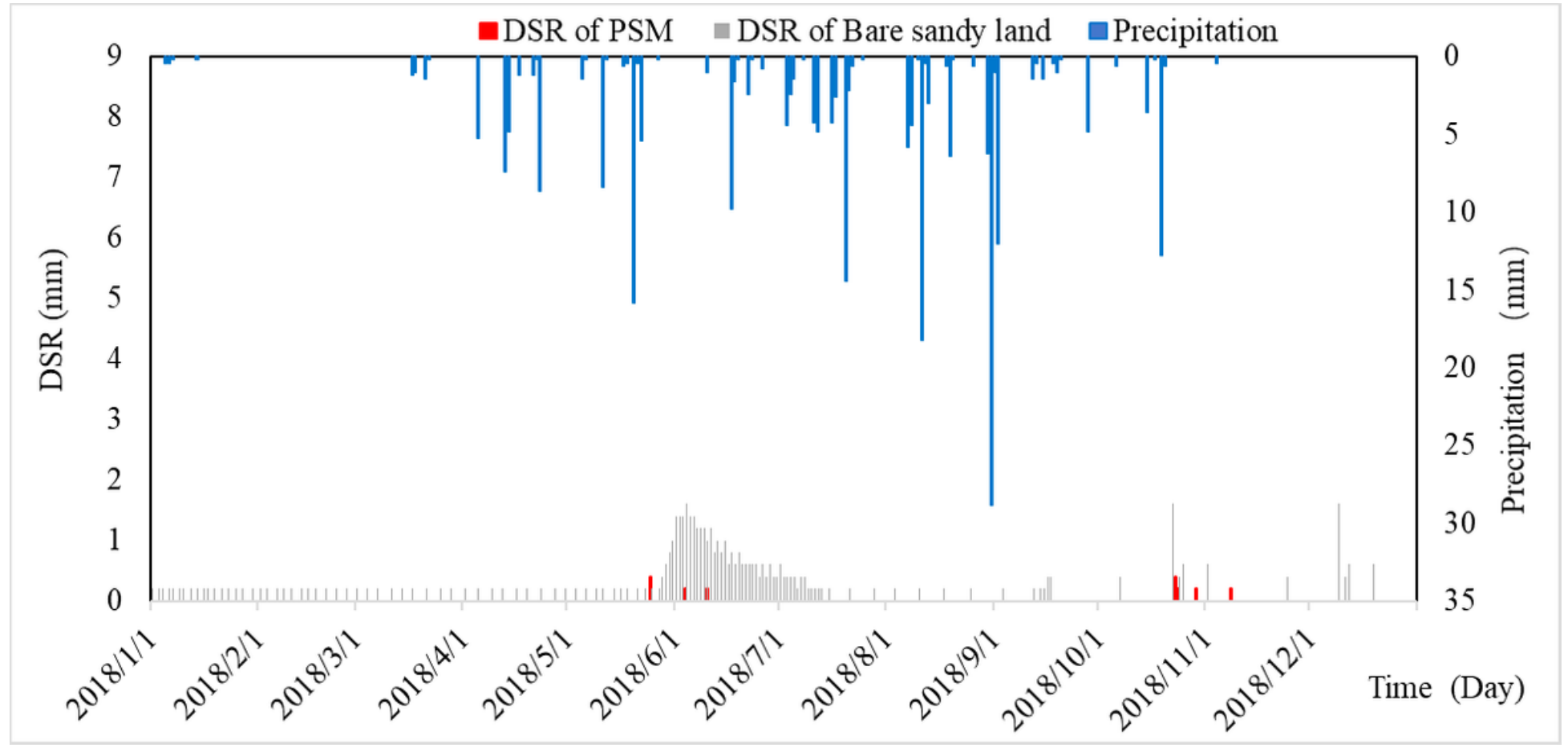

Figure 11

Precipitation and DSR dynamic change in 2018. 
0.25

0.2

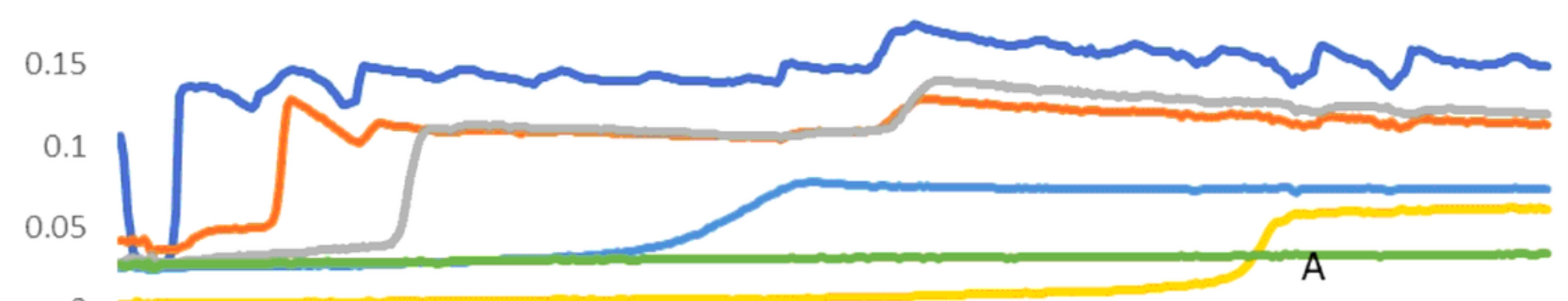

0

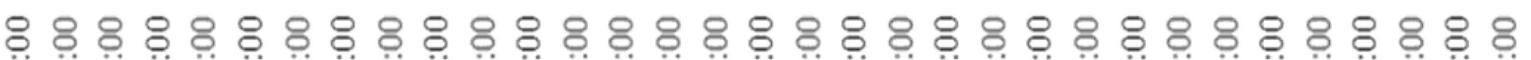
oิ

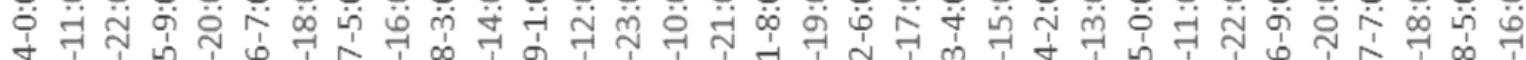
ఫ身

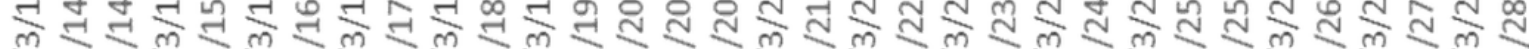

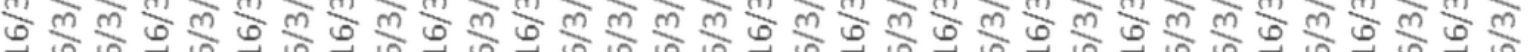

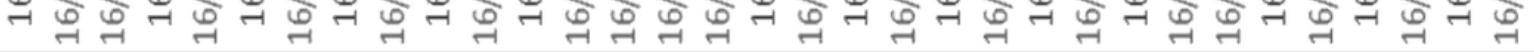

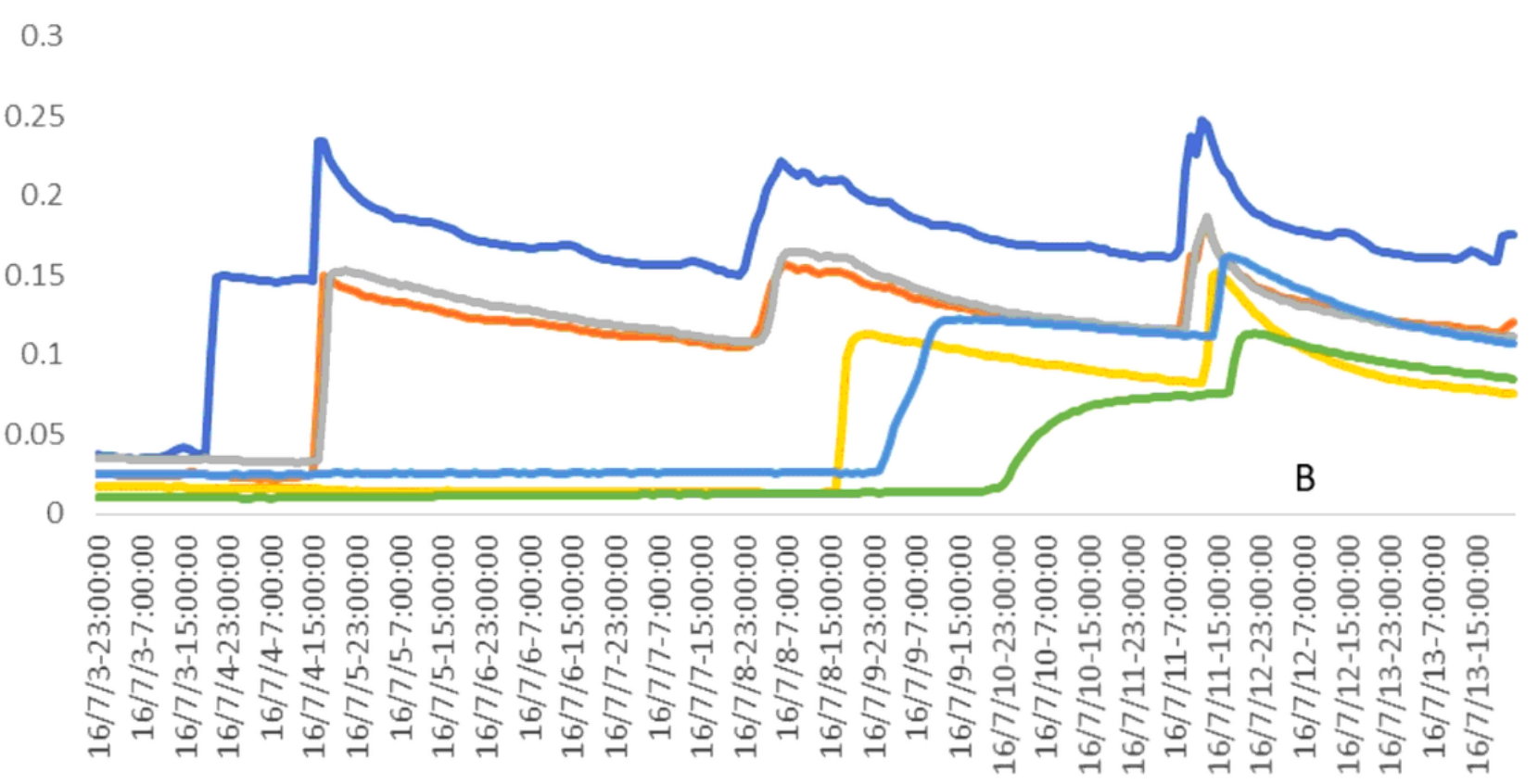

Figure 12

Two recharge process (snowmelt-induced and precipitation-induced) in 2016. 